JADIANE DIONÍSIO

\title{
Análise da força de preensão palmar em recém- nascidos pré-termo e de termo
}

Tese apresentada à Faculdade de Medicina da Universidade de São Paulo, para obtenção do título de Doutor em Ciências

Programa de Pediatria

Orientador: Prof ${ }^{\mathrm{a}}$. Drª . Vera Lúcia Jornada Krebs

São Paulo 
JADIANE DIONÍSIO

\section{Análise da força de preensão palmar em recém- nascidos pré-termo e de termo}

Tese apresentada à Faculdade de Medicina da Universidade de São Paulo, para obtenção do título de Doutor em Ciências

Programa de Pediatria

Orientador: Profa ${ }^{\text {. Dra }}$. Vera Lúcia Jornada Krebs

(Versão corrigida. Resolução CoPGr 5890, de 20 de dezembro de 2010. A versão original está disponível na Biblioteca FMUSP)

São Paulo 
Dados Internacionais de Catalogação na Publicação (CIP)

Preparada pela Biblioteca da

Faculdade de Medicina da Universidade de São Paulo

Creprodução autorizada pelo autor

\section{Dionísio, Jadiane}

Análise da força de preensão palmar em recém-nascidos pré-termo e de termo / Jadiane Dionísio. -- São Paulo, 2012.

Tese(doutorado)--Faculdade de Medicina da Universidade de São Paulo.

Programa de Pediatria.

Orientadora: Vera Lúcia Jornada Krebs.

Descritores: 1.Recém-nascido 2.Prematuro 3.Sistema nervoso central 4.Lateralidade funcional 5.Força da mão 6.Atividade motora

USP/FM/DBD-124/12 
"A alegria não chega apenas no encontro do achado, mas faz parte do processo da busca. E ensinar e aprender não pode dar-se fora da procura, fora da boniteza e da alegria".

Paulo Freire 


\section{DEDICATÓRIA}


Dedico este trabalho aos meus pais João Jair Dionísio e Sônia Regina de Santi Dionísio que sempre me apoiaram e trabalharam para proporcionar a minha formação. Aos meus irmãos Jeferson Dionísio, Jackson Dionísio e Tatiani Roberta Daniel Dionísio que apesar de não entenderem minhas pesquisas me incentivaram, através de brincadeiras, desafios e perguntas frequentes. A minha madrinha Nilza de Santi Chamas, a qual esteve de prontidão para meus desabafos e pedidos. E a minha "família cientifica": Eloisa Tudella, Marcus Vinicius Marques de Moraes, Ruy Jornada Krebs e Vera Lúcia Jornada Krebs por todo o suporte, mesmo quando longe, nos momentos de dificuldade, dúvidas, ou inspirações acadêmicas. 
AGRADECIMENTOS 
Agradeço a Deus por me proporcionar tantas alegrias e nunca me abandonar, mesmo quando me afasto ou duvido de suas obras.

Aos meus pais, os quais sempre me apoiaram nas mais diversas decisões mostrando os pontos fortes e fracos de cada escolha. Por me tratarem não só como filha, mas como um ser humano responsável pelos seus atos e consequências. Por me ensinarem que o importante não é o final, mas sim o caminho que trilhamos com dignidade, sabedoria e respeito. Obrigada, vocês são responsáveis pelo que me tornei e agradeço muito por isso. Amo vocês!

Aos meus irmãos, cunhada, tios, tias, primos, primas, madrinha e todos da família. Agradeço a cada um, mesmo aqueles que não me ajudaram cientificamente, mas que sempre fizeram presentes em pensamentos e orações.

Aos meus antigos amigos Natália Dicler, Gustavo Teixeira Caprio, Matheus Gronner, Vanessa Gabassa, Ana Carolina Campos, Mimi, Rosana Machado, Fernando Tavernari, Arce Correa, Família NENEM. E, aos novos amigos Daniela Oliveira, Carol Zorzetti, Valdeci Dionísio, Ana Paula Rezende Magalhães, Eliane Maria de Carvalho, Célia Regina Lopes, Frederico Deloroso e Sônia Aparecida Paiva, Ana Paula Medina e Daniel. Obrigada por fazerem parte da minha vida nos momentos de descontração, 
trabalho, alegrias e tristezas. Dizem que "amigo é a família que se escolhe", e eu sou grata por me escolherem.

Agradeço aos membros da banca (permanentes e suplentes), por participarem deste trabalho (tanto na qualificação, quanto na defesa), contribuindo com ideias, curiosidades, dúvidas e críticas construtivas as quais me ajudam a expandir conhecimentos.

Agradeço a Faculdade de Medicina da Universidade de São Paulo, seus funcionários (professores, secretários, seguranças, bibliotecários) e ao Berçário Anexo ao Hospital das Clínicas (médicos, fisioterapeutas, chefes, enfermeiros, técnicos, nutricionistas, seguranças, auxiliares) pela contribuição de cada um, seja auxiliando nas ações burocráticas ou simplesmente dividindo espaço e tempo ao meu lado.

Ao meu grande amigo Prof. Dr. Marcus Vinicius Marques de Moraes, o qual sem ele, este trabalho não poderia ser realizado. Obrigada meu amigo pelos longos momentos ao telefone, messenger, facebook, e-mail, mensagens, laboratório, em casa ou em restaurantes, sempre me ouvindo, discutindo resultados, inovando comentários, pesquisando artigos assim como, divertindo-me com histórias, e observações sobre minha vida pessoal. Você se tornou um irmão, com o qual posso desabafar minhas angustias e alegrias sejam da vida profissional ou pessoal. Sou muito grata a você! 
Agradeço a minha mãe acadêmica Profª Drª Eloísa Tudella, se estou aqui hoje é graças ao seu auxílio e sempre serei grata, minha eterna professora, orientadora, co-orientadora, mas agora, e espero que sempre, minha amiga. Agradeço-lhe a cada ensinamento profissional e aos momentos de amizade.

Agradeço ao Prof. Dr. Ruy Jornada Krebs por, juntamente com Marcus, iniciar esse desafio e acreditar em mim, mesmo nunca me conhecendo. Quando me perguntam qual foi a limitação do estudo, penso e chego a conclusão que a maior delas foi não poder conhecê-lo. Sua partida deixou saudades nas pessoas próximas e uma grande frustração em mim por não poder dividir ideias com alguém que me apoiou por intermédios. $\bigcirc$ que me conforta são os artigos publicados, as histórias e memórias contadas com muito carinho por Marcus e Drạ. Vera mostrando o excelente homem que o senhor foi. Obrigada Ruy, este trabalho é seu.

A Prof ${ }^{a}$ Drạ. Vera Lúcia Jornada Krebs, por sua grande experiência, sabedoria, capacidade e coerência. Poder dividir ideias, observar sua liderança e respeito ao próximo, e até mesmo manter conversas casuais, era um método de aprendizagem e crescimento diário. Agradeço-Ihe por tudo que me proporcionou, por acreditar em mim e estar sempre do meu lado. Espero que nossa parceria perdure por muito tempo. 
Esta tese está de acordo com as seguintes normas, em vigor no momento desta publicação:

Referências: adaptado de International Committee of Medical Journals Editors (Vancouver).

Universidade de São Paulo. Faculdade de Medicina. Divisão de Biblioteca e Documentação. Guia de apresentação de dissertações, teses e monografias. Elaborado por Anneliese Carneiro da Cunha, Maria Julia de A.

L. Freddi, Maria F. Crestana, Marinalva de Souza Aragão, Suely Campos Cardoso, Valéria Vilhena. 3a ed. São Paulo: Divisão de Biblioteca e Documentação; 2011.

Abreviaturas dos títulos dos periódicos de acordo com List of Journals Indexed in Index Medicus 
Lista de Abreviaturas

Lista de Siglas

Lista de Símbolos

Lista de Figuras

Lista de Tabelas

Lista de Gráficos

Resumo

Summary

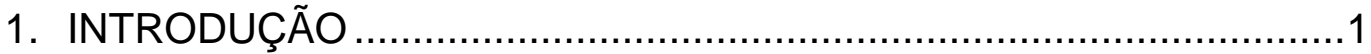

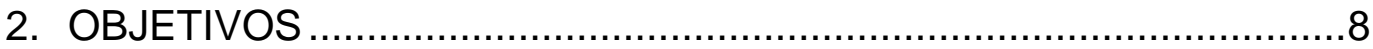

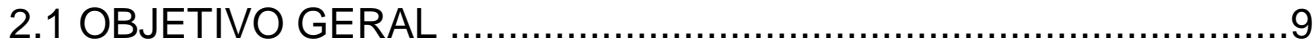

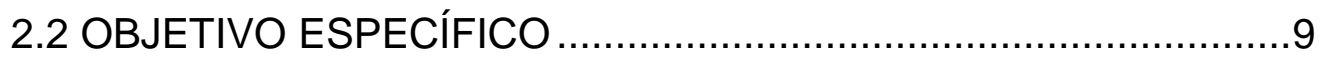

3. MÉTODOS …....................................................................... 10

3.1 CASUÍSTICA ...................................................................

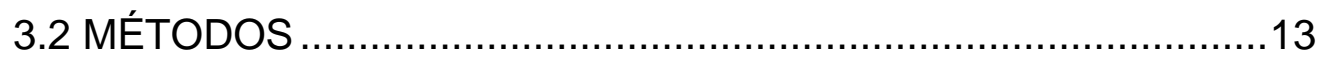

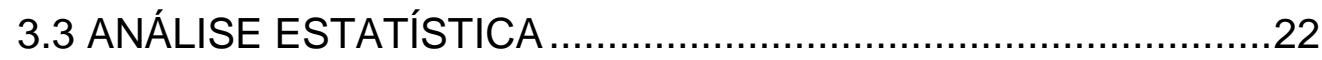

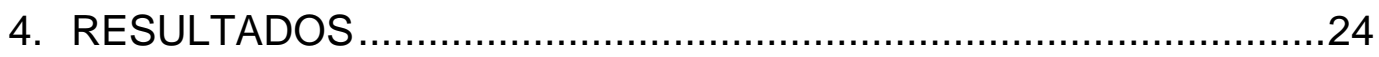

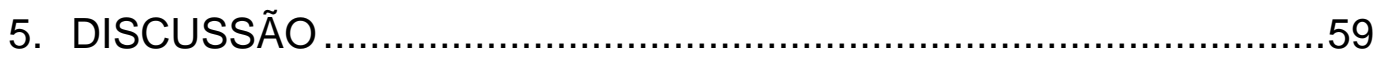

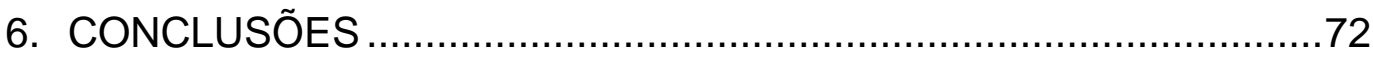

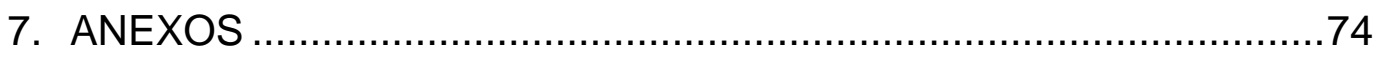

8. REFERÊNCIAS BIBLIOGRÁFICAS .......................................81 
LISTAS 


\section{LISTA DE ABREVIATURAS}

$\begin{array}{ll}\text { et al. } & \text { - e outros } \\ \text { sem } & \text { - semanas } \\ \text { cm } & \text { - centímetro } \\ \text { min } & \text { - minuto }\end{array}$




\section{LISTA DE SIGLAS}

$\begin{array}{ll}\text { SNC } & \text { - Sistema Nervoso Central } \\ \text { RNT } & \text { - Recém-nascido de termo } \\ \text { RNPT } & \text { - Recém-nascido pré-termo } \\ \text { TCLE } & \text { - Termo de Consentimento Livre e Esclarecido } \\ \text { CAPPesq } & - \text { Comissão de Ética para Análise de Projetos de } \\ \text { Pesquisa } & \\ \text { HC-FMUSP } & \text { - Hospital das Clínicas da Faculdade de Medicina da } \\ \text { Universidade de São Paulo }\end{array}$




\section{LISTA DE SÍMBOLOS}

$\begin{array}{ll}\mathbf{m m H g} & \text { - milímetros por mercúrio } \\ \mathbf{g f} / \mathbf{c m}^{2} & \text { - grama força por centímetro ao quadrado } \\ { }^{\circ} \mathbf{C} & \text { - graus Celsius } \\ \mathbf{p} & \text { - índice de probabilidade } \\ \% & \text { - porcentagem } \\ \mathbf{n} & \text { - frequência absoluta } \\ > & \text { - maior que } \\ < & \text { - menor que } \\ \mathbf{g} & \text { - grama } \\ \mathbf{\pm} & \text { - mais ou menos } \\ \mathbf{t} & \text { - t-Student } \\ \mathbf{F} & - \text { Anova } \\ \mathbf{\&} & \text { - e }\end{array}$




\section{LISTA DE FIGURAS}

Figura 1 - Posicionamento do balão de borracha do M-Flex®.....................16

Figura 2 - Registro da força de preensão palmar.....................................18 


\section{LISTA DE TABELAS}

Tabela 1 - Correlação entre as três medidas de preensão palmar realizadas nos grupos pré-termo e de termo entre 12-72 horas de vida. .20

Tabela 2 - Validação entre as três medidas de preensão palmar realizada nos grupos pré-termo e de termo entre 12-72 horas de vida. .21

Tabela 3 - Estatística descritiva das variáveis contínuas e categóricas dos recém-nascidos de termo. .26

Tabela 4 - Estatística descritiva das variáveis contínuas e categóricas dos recém-nascidos pré-termo tardios .27 


\section{LISTA DE GRÁFICOS}

Gráfico 1 - Força de preensão palmar da mão direita e mão esquerda em recém-nascidos de termo entre 12-24 horas de vida .30

Gráfico 2 - Força de preensão palmar entre gênero masculino e feminino em recém-nascidos de termo entre 49-72 horas de vida .33

Gráfico 3 - Força de preensão palmar entre recém-nascidos de termo com 12-24h, 25-48h e 49-72 horas de vida. .35

Gráfico 4 - Tempo de preensão palmar entre gênero masculino e feminino em recém-nascidos pré-termo tardios entre 25-48 horas de vida .39

Gráfico 5 - Tempo de preensão palmar entre gênero masculino e feminino em recém-nascidos pré-termo tardios entre 49-72 horas de vida 41

Gráfico 6 - Força de preensão palmar dos recém-nascidos pré-termo tardios entre 12-24h, 25-48h e 49-72 horas de vida .43

Gráfico 7 - Tempo de preensão palmar dos recém-nascidos pré-termo tardios entre 12-24h, 25-48h e 49-72 horas de vida. .45 
Gráfico 8 - Comparação do tempo de preensão palmar entre recém-nascido de termo versus pré-termo tardio entre 12-24 horas de vida 47

Gráfico 9- Comparação da força de preensão palmar entre recém-nascido de termo versus pré-termo tardio entre 25-48 horas de vida 49

Gráfico 10 - Comparação do tempo de preensão palmar entre recémnascido de termo versus pré-termo tardio entre $25-48$ horas de vida. 51

Gráfico 11- Comparação da força de preensão palmar entre recém-nascido de termo versus pré-termo tardio entre 49-72 horas de vida .53

Gráfico 12- Comparação da força de preensão palmar entre recém-nascidos de termo versus pré-termo tardio com 12-24h, 25-48h e 49-72 horas de vida. 56

Gráfico 13 - Comparação do tempo de preensão palmar entre recémnascidos de termo versus pré-termo tardio com 12-24h, 25-48h e 49-72 horas de vida. .58 
RESUMO 
Dionísio J. Análise da força de preensão palmar em recém-nascidos prétermo e de termo [tese]. São Paulo: Faculdade de Medicina, Universidade de São Paulo; 2012.

O objetivo do estudo foi descrever e comparar a força de preensão palmar em recém-nascidos de termo (RNT) e pré-termo tardios (RNPT) nas primeiras 72 horas de vida. A força de preensão palmar foi avaliada com 0 equipamento $\mathrm{M}$-Flex $\AA^{\circledR}$, sendo realizadas três medidas para cada mão em cada neonato entre 12-24h, 25-48h e 49-72 h de vida. Foi utilizado os testes $\mathrm{t}$-Student e Anova two-way, considerando-se significante $\mathrm{p}<0,05$. Foram estudados 306 recém-nascidos (219 RNT e 87 RNPT),divididos em três grupos. Os RNT apresentaram maior força de preensão quando comparados aos RNPT em cada idade:12-24h ( $t=4,64, p=0,00) ; 25-48 \mathrm{~h}(\mathrm{t}=2,54, \mathrm{p}=0,01$, $\mathrm{t}=8,02, \quad \mathrm{p}=0,00) ; 49-72 \mathrm{~h} \quad(\mathrm{t}=0,95, \mathrm{p}=0,01, \mathrm{t}=1,84, \mathrm{p}=0,06)$. $\mathrm{O}$ mesmo comportamento foi observado na comparação entre as três idades (força: $F=2,67, p=0,00$; tempo $F=2,18, p=0,02$ ). Na análise de cada grupo os RNT apresentaram maior força de preensão entre $49-72 \mathrm{~h}$ de vida, em relação à idade entre 12-24h ( $t=0,22, p=0,01)$ e 25-48h ( $t=0,06, p=0,001)$, enquanto os RNPT apresentaram diminuição da força $(F=3,55, p=0,02)$ e do tempo $(F=23,10, \quad p=0,00)$ de preensão palmar entre 12 e 72 h. Os autores concluíram que houve aumento significativo da força de preensão palmar nas primeiras 72 horas de vida nos RNT. No entanto, os recém-nascidos pré-termo tardios apresentaram diminuição da força de preensão palmar. A variabilidade da força de preensão palmar observada na comparação entre os gêneros indica similaridade nesta faixa etária. Na comparação entre as mãos, direita e esquerda, não foi identificada preferência manual.

Descritores: Recém-nascido; Prematuro; Sistema nervoso central; Lateralidade funcional; Força da mão; Atividade motora 
Dionisio J. Analysis of the palmar grasping strength in preterm and full-term infants [thesis]. São Paulo: Faculdade de Medicina, Universidade de São Paulo; 2012.

The objective of this study was to describe and compare the palmar grasping strength of full-term (FT) and late preterm (LPT) infants in the first 72 hours of life. The palmar grasping strength was assessed with the M-Flex $\AA$ equipment, where three measures were performed for each hand of each infant at ages 12-24 h 25-48 h and 49-72 h of life. The t-Student and two-way ANOVA was used, being considered significant at $p<0.05$. Overall, 306 infants (219 FT and 87 LPT) were studied, being divided into three groups. FT infants had higher grasping strength and time when compared to LPT infants at the following ages: $12-24 \mathrm{~h}(\mathrm{t}=4.64, \mathrm{p}=0.00), 25-48 \mathrm{~h}(\mathrm{t}=2.54, \mathrm{p}=$ $0.01, t=8.02, p=0.00), 49-72 h(t=0.95, p=0.01, t=1.84, p=0.06)$. The same behavior was observed in the comparison between the three ages (strength: $t=2.67, p=0.00$; time $t=2.18, p=0.02$ ). In the analysis of each group, FT infants had higher grasping strength between 49 and 72 hours of life when compared to the age between 12 and $24 \mathrm{~h}(\mathrm{t}=0.22, \mathrm{p}=0.01)$ and between 25 and $48 \mathrm{~h}(\mathrm{t}=0.06, \mathrm{p}=0.001)$, while LPT infants showed reduced palmar grasping strength $(F=3.55, p=0.02)$ and time $(F=23.10, p=0.00)$ between 12 and $72 \mathrm{~h}$. The authors concluded that there was significant increase in the palmar grasping strength in the first 72 hours of life for FT infants. However, late preterm infants showed lower palmar grasping strength. The variability in the palmar grasping strength observed in the comparison between genders indicates similarity in this age group. In the comparison between right and left hands, no manual preference was identified.

Keywords: Newborn; Preterm; Central nervous system; Function laterality; Hand strength; Motor activity 
A teoria de seleção de grupo neuronal prediz que o desenvolvimento motor ocorre devido à organização e maturação cerebral, sendo a estrutura e função selecionadas de acordo com os repertórios neurais de variabilidade primária e secundária (Hadders-Algra, 2002).

O repertório neural de variabilidade primária é representado por grupos neurais múltiplos, onde a estrutura celular e a conectividade são determinadas, basicamente, por informações genéticas. O repertório primário é variável devido à dinâmica genética (regulação das divisões celulares, adesão, migração, extensão e morte) e está relacionado com o grau de mielinização, arborização e formação sináptica representando a evolução do Sistema Nervoso Central (SNC) (McGraw, 1944; Gesell \& Amatruda, 1945; Capute \& Accardo, 1996; Changeus, 1997; Hadders-Algra, 2000a)

A maturação do SNC segue uma ordem pré-determinada céfalo-caudal e próximo-distal (Gesell \& Amatruda, 1945; McGraw, 1944; Shirley, 1973), possibilitando maior plasticidade e armazenamento de informações e adaptação ao ambiente (Allen \& Capute, 1990; Johnston et al., 2009). Este processo é transcrito por movimentos involuntários, conhecidos como reflexos e reações, que aparecem na vida fetal e se estendem pela infância (Vles et al., 1989; Hadders-Algra \& Touwen, 1992; Hadders-Algra, 2000a; Colson, Meek, \& Hawdon, 2008). São considerados mecanismos de 
sobrevivência para agrupar informações, buscar alimento e realizar reações protetoras (Capute et al., 1984; Colson, Meek, \& Hawdon, 2008).

Estes comportamentos são específicos para repertórios neurais supraespinhais, traduzindo-se por ajustes posturais, sinergias e movimentos de amplitudes variáveis, que refletem a atividade subcortical (Prechtl, 1990; Changeux, 1997; Hadders-Algra, 2000a; Johnston et al., 2009).

A maioria destes movimentos estão presentes durante a primeira infância, quando inicia a transição de meta não direcionada (comportamento involuntário) para meta direcionada (movimentos espontâneos) (HaddersAlgra, 2000b). O primeiro movimento de transição entre as metas dos membros superiores é a manipulação mútua das mãos. O recém-nascido apresenta o comportamento de preensão palmar (meta não direcionada), o qual permanece nos quatro primeiros meses de vida. Após este período a meta torna-se direcionada, tais como alcance e apreensão dos objetos. Com o passar do tempo, esta ação torna-se mais habilidosa, surgindo a variabilidade secundária (Hadders-Algra, 2000b).

A variabilidade secundária inicia-se aproximadamente no $4^{0}$ mês de idade e representa a habilidade da atividade motora e postural em selecionar estratégias efetivas para os diferentes tipos de tarefas (Hadders-Algra \& Touwen, 1992; Hadders-Algra, 2002). Estas poderão ser fáceis, como alcance, ou complexas, como manipulação de objetos. As estratégias dividem-se em tarefas com direção específica e aspectos temporais da atividade muscular, onde o sistema nervoso central, o meio ambiente e a tarefa a ser executada são responsáveis pela escolha e ação do individuo 
(Hadders-Algra, 2002). Embora esta sequência de desenvolvimento motor possa ser observada no recém-nascido de termo (RNT), acredita-se que no recém-nascido pré-termo (RNPT), este processo esteja incompleto (DeGroot, 2000; Miceli et al., 2000; Lekskulchai \& Cole, 2001; Jeng Chen \& Yau, 2002; Rieko et al., 2003).

A prematuridade e o baixo peso ao nascimento estão associados à imaturidade do sistema nervoso central, ao atraso no desenvolvimento motor, prejuízo nas habilidades motoras e ocasionalmente morte prematura (Fallang, Saugstad \& Hadders-Algra, 2003; Weiss, 2005, Allen, 2008; Mutlu, Livanelioglu \& Korkmaz, 2010).

Observa-se que as aquisições motoras dos recém-nascidos pré-termo, tais como, controle de cabeça, controle de tronco, alcance e marcha, são alcançadas em ritmo mais lento em relação ao recém-nascido de termo (Rieko et al., 2003).

Além disso no recém-nascido pré-termo podem ser observados o desaparecimento prematuro e/ou ausência de reflexos, assim como a permanência exacerbada destes após a idade critica (Zurich, 1993; Rieko et al., 2003; Guimarães \& Tudella, 2003; Olhweiler, Silva \& Rotta 2005). Como consequência haverá prejuízo na emersão das habilidades e alteração do desenvolvimento motor (Zurich, 1993; Rieko et al., 2003; Olhweiler, Silva \& Rotta, 2005).

O comportamento de preensão palmar está presente no lactente, sendo sua intensidade mais forte durante o primeiro mês e diminuindo de forma gradual até desaparecer por volta de quatro meses de idade (Zafeiriou, 
Tikoulas \& Kremenopoulos,1995; Tudella, Oish \& Bergamasco, 2000; Tan, 2002). A presença exacerbada após o quinto mês, ou ausência desde o nascimento constitui um importante sinal de alteração neurológica (Pedroso \& Rotta; 1997, Geerts, et al., 2003; Walterfang \& Velakoulis, 2005).

Um dos grandes indicativos de presença ou ausência da preensão palmar é a força muscular. Futagi, Suzuki e Goto (1999), ao avaliar o comportamento de preensão palmar, observaram assimetria da resposta entre os lactentes, diagnosticando paralisia cerebral e déficits motores, entre outras alterações. Estes autores concluíram que a resposta negativa ou diminuída da preensão palmar está diretamente relacionada a disfunções neuromotoras. Guimarães e Tudella (2003) analisaram a importância da avaliação dos reflexos e reações em lactentes aparentemente saudáveis. Os autores destacaram que a permanência de alguns reflexos, assim como a ausência ou diminuição de outros, está interligada às modificações do desenvolvimento neurossensoriomotor.

Em revisão sistemática Zafeiriou (2004) enfatiza que a avaliação do comportamento involuntário é um método rápido, fácil, com resultados confiáveis que, juntamente com escalas de avaliação motoras, podem avaliar a integridade do SNC de recém-nascidos e lactentes e diagnosticar distúrbios motores.

$\mathrm{Na}$ prática clínica avalia-se o comportamento de preensão palmar posicionando o dedo do examinador ou um objeto fino e roliço na base dos metacarpos dos três últimos dedos (médio, anelar e mínimo) do recémnascido, que ao ser estimulado gera flexão dos dedos, fechando-os 
fortemente, sem fletir o polegar (Dubowitz, Mercuri \& Dubowitz, 1998; Mercuri, et al., 2005; Glick, 2005; Amiel-Tison, 2006; Romeo et al., 2007). Por se tratar de uma técnica baseada na experiência e sensibilidade do examinador, seu resultado pode apresentar variações importantes.

Moraes et al. (2011) desenvolveram um equipamento para medir a intensidade da força de preensão palmar. O M-Flex® é um equipamento não invasivo, leve e portátil capaz de detectar precisamente a força de preensão palmar dos lactentes através das unidades físicas $\left(\mathrm{mmHg}\right.$ e $\left.\mathrm{gf} / \mathrm{cm}^{2}\right)$, possibilitando maior acurácia na avaliação motora de recém-nascidos e lactentes.

Uma vez que a força de preensão palmar desenvolve-se gradualmente nos primeiros meses de vida, faz-se importante compreender esse comportamento típico e detectar prováveis mudanças que ocorram ainda no período neonatal em recém-nascidos de termo e pré-termo. Portanto, a avaliação da preensão palmar representa um instrumento valioso no diagnóstico precoce de alterações neurológicas no recém-nascido.

Tendo em vista a importância da avaliação, a subjetividade das técnicas e a ausência de equipamentos capazes de quantificar com exatidão a força de preensão palmar dos recém-nascidos, assim como a lacuna existente na literatura sobre avaliações desta natureza, pesquisas nesta área são necessárias.

Diante do exposto, as hipóteses a serem testadas foram: recémnascidos pré-termo tardios apresentam diferença no comportamento de preensão palmar quando comparados com recém-nascidos de termo; a força 
e o tempo de preensão palmar irá se modificar nas primeiras 72 horas de vida; haverá diferença da força de preensão palmar entre os gêneros masculino e feminino; haverá diferença da força da preensão palmar da mão direita com a mão esquerda. 


\section{OBJETIVOS}




\subsection{OBJETIVO GERAL}

Descrever e comparar a força e o tempo de preensão palmar em recém-nascidos de termo e pré-termo tardios nas primeiras 72 horas de vida.

\subsection{OBJETIVOS ESPECÍFICOS}

- Descrever a força e o tempo de preensão palmar em recém-nascidos de termo e pré-termo tardios entre 12-24, 25-48 e 49-72 horas de vida.

- Comparar a força e o tempo de preensão palmar entre recémnascidos de termo e pré-termo tardios com 12-24, 25-48 e 49-72 horas de vida.

- Comparar a força e o tempo de preensão palmar entre os gêneros masculino e feminino em recém-nascidos de termo e pré-termo tardios.

- Comparar a força e o tempo de preensão palmar entre a mão direita e a mão esquerda nos recém-nascidos de termo e pré-termo tardios. 
MÉTODOS (20) 


\subsection{CASUÍSTICA}

Foram estudados 306 recém-nascidos de ambos os gêneros divididos em dois grupos:

- Grupo RNT: 219 recém-nascidos de termo (idade gestacional entre 37 e $41^{6 / 7}$ semanas)

- Grupo RNPT: 87 recém-nascidos pré-termo tardios (idade gestacional de 34 a $36^{6 / 7}$ semanas)

\section{Cálculo do tamanho da amostra}

A amostra foi calculada considerando: Desvio padrão $=5.0000$; Erro máximo da estimativa $=1.0000 ;$ Nível de significância $=5 \%$ (Bussab \& Moretin, 2002).

No período de 12 meses foram admitidos 1810 recém-nascidos no Berçário Anexo à Maternidade do Hospital das Clínicas da Faculdade de Medicina da Universidade de São Paulo (FMUSP). O valor do desvio padrão foi estabelecido a partir da análise do número de altas hospitalares destes neonatos (1589 recém-nascidos).

O tamanho da amostra total foi de 96 recém-nascidos, sendo o valor mínimo para cada grupo de 43 recém-nascidos (Anexo I). 


\section{Critérios de inclusão}

Foram incluídos neste estudo os recém-nascidos que apresentaram as seguintes condições:

- Recém-nascidos de termo, com Apgar igual ou superior a 7 no $5^{\circ}$ minuto de vida, com idade gestacional entre 37 e $41^{6 / 7}$ semanas, avaliados pela ultra-sonografia precoce e pela data da última menstruação (DUM) segundo a regra de Naegele, sem complicações clínicas.

- Recém-nascidos pré-termo tardios, com idade gestacional entre 34 e $36^{6 / 7}$ semanas, Apgar igual ou superior a 7 no $5^{\circ}$ minuto, avaliados pela ultra-sonografia precoce e pela data da última menstruação (DUM) segundo a regra de Naegele, hemodinamicamente estáveis, sem complicações clínicas.

\section{Critérios de Exclusão}

Foram excluídos os recém-nascidos submetidos à fototerapia e aqueles com malformações congênitas, síndromes genéticas, distúrbios neurológicos e alterações metabólicas, assim como, filhos de mães usuárias de tranquilizantes (medicamentos diazepínicos) ou drogas ilícitas. Foram também excluídos todos os recém-nascidos que apresentaram alterações no exame de ultrassonografia de crânio. 


\subsection{MÉTODOS}

Foi realizado um estudo de corte-transversal com caráter semiexperimental, previamente aprovado pela Comissão de Ética para Análise de Projetos de Pesquisa - CAPPesq (protocolo №1250/2009- Anexo II). Para cada recém-nascido as medidas da força de preensão palmar foram realizadas da seguinte forma:

- Recém-nascido de termo: avaliação única de cada recém-nascido entre 12 e $72 \mathrm{~h}$ de vida.

- Recém-nascido pré-termo tardio (com idade gestacional de 34 a $36^{6 / 7}$ semanas): avaliação única de cada recém-nascido pré-termo tardio, entre 12 e $72 \mathrm{~h}$ de vida.

As variáveis analisadas foram: idade gestacional, comprimento ao nascimento, perímetro cefálico, peso de nascimento, peso no dia da avaliação, estado comportamental, tamanho das mãos, idade em horas, tempo de preensão palmar e força de preensão palmar.

Para todos os recém-nascidos foram preenchidas duas fichas de dados contendo:

a) Identificação - condições de nascimento, dados maternos e perinatais e condições clínicas (Anexo III);

b) Avaliação do estado comportamental, segundo a escala comportamental de Prechtl e Beintema (1964, Anexo IV). 
Para a manutenção adequada das condições ambientais da sala onde foi realizada a pesquisa, foi mantida temperatura entre $25^{\circ}$ e $26^{\circ} \mathrm{C}$, (aferida por um termômetro digital graduado em graus Celsius), com iluminação adequada e pouco ruído externo.

O peso do recém-nascido foi aferido pelas enfermeiras do berçário anexo a maternidade, utilizando uma balança pediátrica digital; para determinar o comprimento corporal, perímetro cefálico e tamanho das mãos foram utilizadas régua antropométrica e fita métrica, respectivamente. $\mathrm{O}$ tamanho das mãos foi determinado através da medida em centímetros do comprimento (distância entre o osso escafoide e a terceira falange do dedo médio) e circunferência (distância transversal entre o segundo e o quinto metacarpo).

\section{Medida da Força de Preensão Palmar}

A força de preensão palmar foi medida através do equipamento $M$ Flex®. Trata-se de um procedimento indolor e não invasivo. $\mathrm{O}$ equipamento é composto por um sistema com auto-calibração, que é acionado quando o examinador pressiona a tecla início, registrando, sob forma gráfica e numérica, a força de preensão palmar aplicada sobre um balão de borracha. O equipamento registra o tempo durante o qual o balão de borracha, que tem grau de dureza de 40 shore e espessura de $1,25 \mathrm{~mm}$, é pressionado, assim como a pressão máxima e média aplicada, transcritos em $\mathrm{mmHg}$ (milímetros de mercúrio) e gf/cm² (grama-força por centímetro ao quadrado). 
Os dados foram armazenados em um pen-drive que, ao ser transferido para um computador Core2, foi interpretado e analisado pelo software TodMed MFlex®, específico para gerenciamento do equipamento. $\mathrm{O}$ equipamento $\mathrm{M}$ Flex® é validado para neonatos de termo até 4 meses de idade pós-natal (Moraes et.al., 2011).

As coletas dos recém-nascidos de termo e pré-termo tardios, entre $12 \mathrm{e}$ 72 horas de vida, foram realizadas no Berçário Anexo à Maternidade do Hospital das Clínicas da Faculdade de Medicina da Universidade de São Paulo (HC-FMUSP). O protocolo foi aplicado no período da manhã no intervalo entre duas mamadas, após a obtenção do consentimento informado (Termo de Consentimento Livre e Esclarecido - TCLE).

Antes do início do procedimento, o estado comportamental do recémnascido foi avaliado pela pesquisadora, sendo incluídos os neonatos que apresentaram estado de alerta nível 4 (Inativo) ou 5 (Ativo). Os recémnascidos com grau 1 (sono profundo), 2 (sono leve/ativo), 3 (sonolento/ intermediário) e 6 (choro), não foram avaliados naquele momento.

Concluída a escala comportamental, foi realizada a aferição das medidas antropométricas (peso, comprimento corporal, comprimento e circunferência das mãos), seguida do posicionamento do recém-nascido em supino, em seu próprio berço com a cabeça na linha média. Após o posicionamento, o examinador estimulou a abertura da mão do recémnascido, posicionando o balão de borracha do $M-F l e x{ }^{\circledR}$ na base dos três últimos dedos (médio, anelar e mínimo), não permitindo o deslizamento do balão sobre a região descrita (Moraes et.al., 2011; Figura 1). 


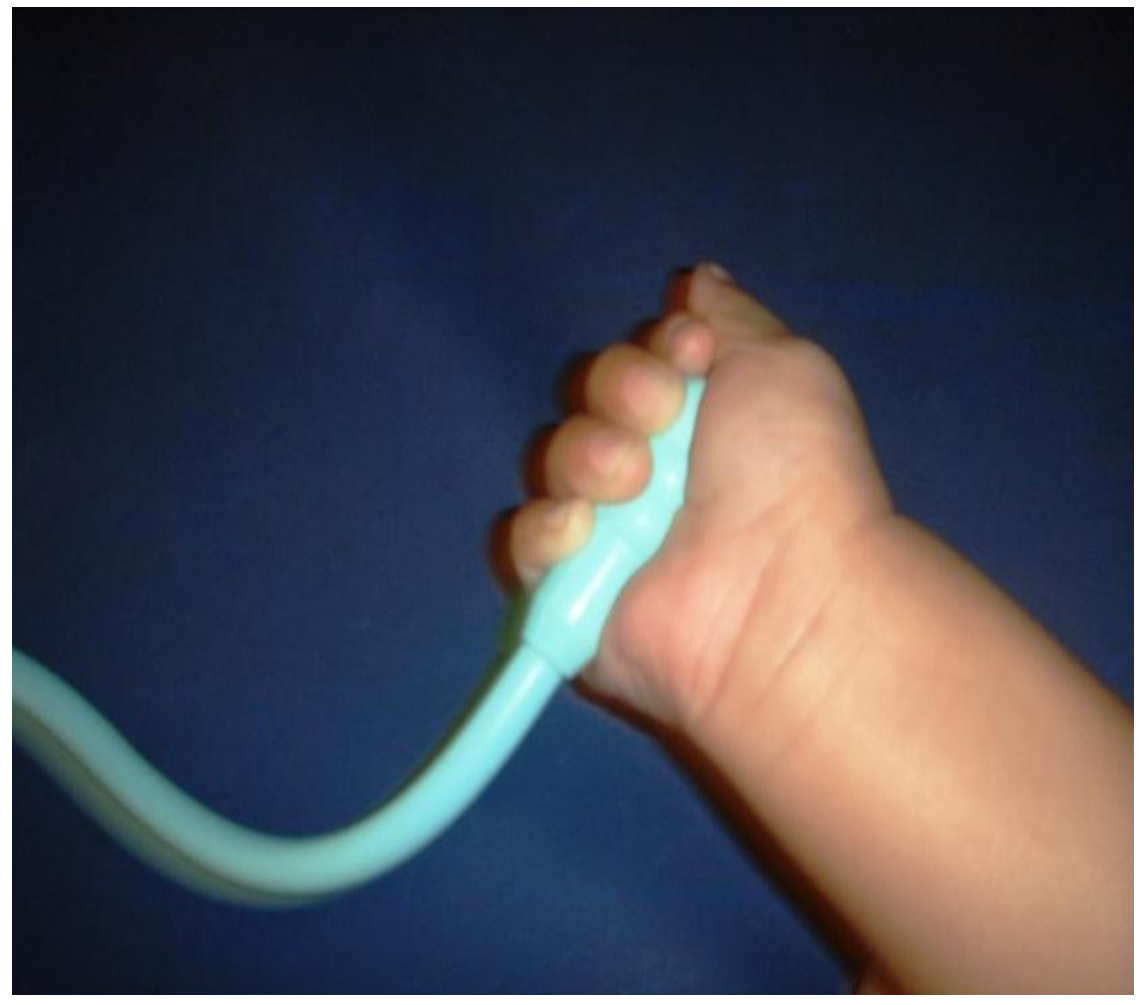

Figura 1. Posicionamento do balão de borracha do $M-F l e x ®$ 
A coleta foi feita desde o início do registro da curva da força pelo aparelho, quando o examinador pressionou a tecla "iniciar", sendo interrompida quando o recém-nascido parou de realizar a preensão palmar.

Foram realizadas três medidas em cada mão, iniciando a coleta sempre pela mão esquerda, sendo o tempo total máximo de avaliação de aproximadamente seis minutos. Entre cada medida obteve-se um tempo de 20 segundos para registro da medida anterior e re-calibração do equipamento (Figura 2).

O aparelho armazenou o nome dos recém-nascidos e as leituras (gráficas e numéricas), que foram transferidas para um computador para a interpretação das variáveis contínuas (idade, peso de nascimento, peso no dia da avaliação, estado comportamental, comprimento físico e tamanho das mãos) e categóricas (prematuridade, idade gestacional, gênero, tempo e força de preensão palmar). 


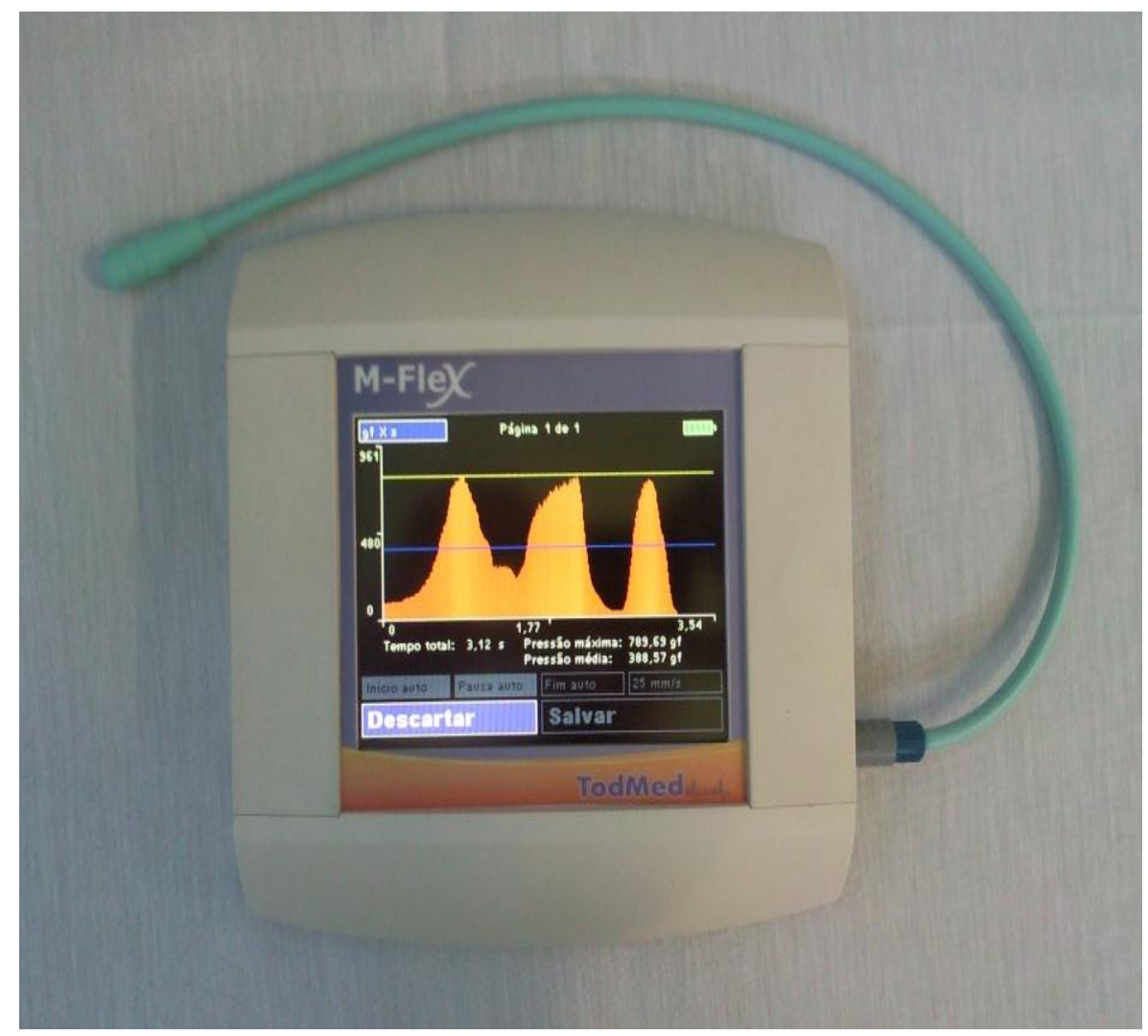

Figura 2. Registro da força de preensão palmar 
O resultado final da preensão palmar foi o valor representado pela média das três medidas realizadas. Esse tipo de análise foi escolhido com o propósito de obter o resultado mais fidedigno. Ao analisar cada medida individualmente e confrontá-las foi observada normalização entre elas, enfatizando assim que o comportamento de preensão palmar foi semelhante nas três medidas avaliadas (Tabelas 1 e 2). 
Tabela 1. Correlação entre as três medidas de preensão palmar realizadas nos grupos pré-termo tardios e de termo entre 12-72 horas de vida

\section{Força Normalizada}

\begin{tabular}{|c|c|c|c|c|c|c|}
\hline Medida & Medida & Média & Erro & $\mathbf{P}$ & $\begin{array}{c}\text { Limite } \\
\text { Inferior* }\end{array}$ & $\begin{array}{c}\text { Limite } \\
\text { Superior* }\end{array}$ \\
\hline \multirow[t]{2}{*}{ Primeira } & Segunda & 0,01 & 0,02 & 0,75 & $-0,03$ & 0,06 \\
\hline & Terceira & 0,00 & 0,02 & 0,96 & $-0,04$ & 0,05 \\
\hline \multirow[t]{2}{*}{ Segunda } & Primeira & $-0,01$ & 0,02 & 0,75 & $-0,06$ & 0,03 \\
\hline & Terceira & $-0,01$ & 0,02 & 0,88 & $-0,06$ & 0,04 \\
\hline \multirow[t]{2}{*}{ Terceira } & Primeira & $-0,00$ & 0,02 & 0,96 & $-0,05$ & 0,04 \\
\hline & Segunda & 0,01 & 0,02 & 0,88 & $-0,04$ & 0,06 \\
\hline
\end{tabular}


Tabela 2. Confiabilidade entre as três medidas de preensão palmar realizada nos grupos pré-termo tardios e de termo entre 12-72 horas de vida

\begin{tabular}{ccccccccc}
\hline \multicolumn{2}{c}{ Medidas } & \multicolumn{2}{c}{ Válidas } & \multicolumn{2}{c}{ Perdidas } & \multicolumn{2}{c}{ Total } \\
& & & Número & $\%$ & Número & $\%$ & Número & $\%$ \\
\hline Força de & Primeira & 438 & 100 & 0 & 0,0 & 438 & 100 \\
Preensão & Segunda & 437 & 99,8 & 1 & 0,2 & 438 & 100 \\
Palmar & Terceira & 435 & 99,3 & 3 & 0,7 & 438 & 100 \\
& & & & & & & & \\
\hline
\end{tabular}


As variáveis contínuas e categóricas foram comparadas nas seguintes ocasiões:

\section{Análise Intra-grupo}

Descrição e comparação da força e tempo de preensão palmar de cada grupo;

- Recém-nascidos de termo: idade (12-24h, 25-48h e 49-72 horas de vida), preferência manual (mão direita versus esquerda) e gênero (feminino versus masculino);

- Recém-nascidos pré-termo tardios: idade (12-24h, 25-48h e 49-72 horas de vida), preferência manual (mão direita versus esquerda) e gênero (feminino versus masculino).

\section{Análise Inter-grupo}

Comparação da força e tempo de preensão palmar entre os grupos;

- Recém-nascidos de termo com pré-termo tardios: idade (1224h, 25-48h e 49-72 horas de vida).

\subsection{ANÁLISE ESTATÍSTICA}

As variáveis contínuas foram apresentadas por valores de média, desvio-padrão, mínima e máxima indicando a variabilidade dos dados. As 
variáveis categóricas foram descritas sob a forma de frequência relativa (percentual) e absoluta (n), de cada categoria. Os dados foram analisados através dos testes paramétricos t-Student e ANOVA Two-way, com teste post-hoc de Tukey, considerando significância 0 valor de $p<0,05$. 
RESULTADOS

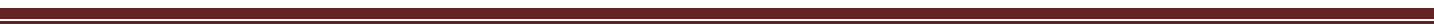


Foram estudados 306 recém-nascidos, sendo 219 recém-nascidos de termo e 87 recém-nascidos pré-termo tardios.

$\mathrm{Na}$ tabela 3 e 4 são apresentadas as estatísticas descritivas das variáveis Apgar, IG, perímetro cefálico, peso ao nascer e no dia da avaliação, comprimento corporal ao nascer e do dia da avaliação, comprimento e circunferência das mãos e estado comportamental. 
Tabela 3. Estatística descritiva das variáveis contínuas e categóricas dos recém-nascidos de termo

\begin{tabular}{|c|c|c|c|}
\hline GRUPO & CARACTERÍSTICAS & MÉDIA & DP \\
\hline \multirow{11}{*}{ 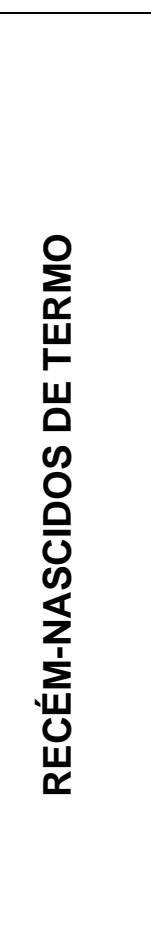 } & Idade gestacional (sem) & 38,81 & 1,50 \\
\hline & Peso ao nascer (g) & $3.360,00$ & 159,65 \\
\hline & Comprimento corporal ao nascer $(\mathrm{cm})$ & 48,15 & 3,53 \\
\hline & Peso no dia da avaliação (g) & $3.044,00$ & 449,67 \\
\hline & Comprimento corporal no dia da avaliação $(\mathrm{cm})$ & 48,11 & 2,21 \\
\hline & Circunferência MD $(\mathrm{cm})$ & 9,14 & 0,64 \\
\hline & Comprimento MD $(\mathrm{cm})$ & 6,50 & 0,44 \\
\hline & Circunferência ME $(\mathrm{cm})$ & 9,14 & 0,64 \\
\hline & Comprimento ME $(\mathrm{cm})$ & 6,50 & 0,44 \\
\hline & Perímetro cefálico $(\mathrm{cm})$ & 34,42 & 1,89 \\
\hline & Estado comportamental & 4,49 & 0,50 \\
\hline
\end{tabular}


Tabela 4. Estatística descritiva das variáveis contínuas e categóricas dos recém-nascidos pré-termo tardios

\begin{tabular}{|c|c|c|c|}
\hline GRUPO & CARACTERISTICAS & MÉDIA & DP \\
\hline \multirow{11}{*}{ 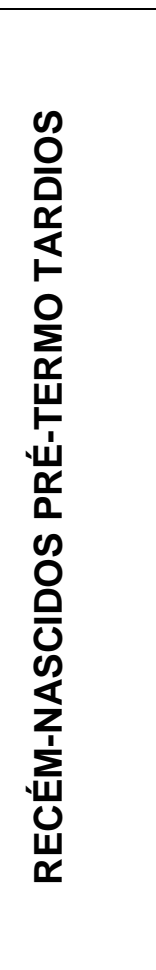 } & Idade gestacional (sem) & 35,91 & 0,70 \\
\hline & Peso ao nascer (g) & $2.556,00$ & 350,59 \\
\hline & Comprimento corporal ao nascer $(\mathrm{cm})$ & 45,66 & 2,36 \\
\hline & Peso no dia da avaliação $(\mathrm{g})$ & $2.458,00$ & 352,01 \\
\hline & Comprimento corporal no dia da avaliação (cm ) & 45,63 & 2,44 \\
\hline & Circunferência MD ( cm ) & 8,5 & 0,71 \\
\hline & Comprimento MD (cm) & 6,24 & 0,47 \\
\hline & Circunferência ME (cm) & 8,48 & 0,68 \\
\hline & Comprimento ME $(\mathrm{cm})$ & 6,23 & 0,49 \\
\hline & Perímetro cefálico $(\mathrm{cm})$ & 33,01 & 1,35 \\
\hline & Estado comportamental & 4,51 & 0,50 \\
\hline
\end{tabular}


A seguir serão apresentados os resultados referentes aos comportamentos de força e tempo de preensão palmar.

\section{Recém-Nascido de Termo}

Foram analisados 219 recém-nascidos de termo de ambos os gêneros, que preencheram os critérios de inclusão. A idade gestacional média foi de $38,81( \pm 1,50)$ semanas. Os recém-nascidos foram divididos em três subgrupos:

- Grupo 1: 46 recém-nascidos com idade média de 22:4( $\pm 0,25)$ horas de vida;

- Grupo 2: 106 recém-nascidos com idade média de 44:35 $( \pm 0,22)$ horas de vida;

- Grupo 3: 67 recém-nascidos com idade média de 67:13( $\pm 0,23)$ horas de vida. 
Recém-nascido de termo entre 12-24 horas de vida

Foi observada diferença significativa da variável força de preensão entre as mãos, sendo maior a força na mão esquerda $(t=-2,43, p=0,01)$ quando comparada com a mão direita (Gráfico 1).

Nas variáveis gênero $(t=1,69, p=0,09)$ e tempo de preensão palmar $(\mathrm{t}=-0,19, \mathrm{p}=0,84)$ não foram observadas diferenças significativas. 
Gráfico 1. Força de preensão palmar da mão direita e mão esquerda em recém-nascidos de termo entre 12-24 horas de vida

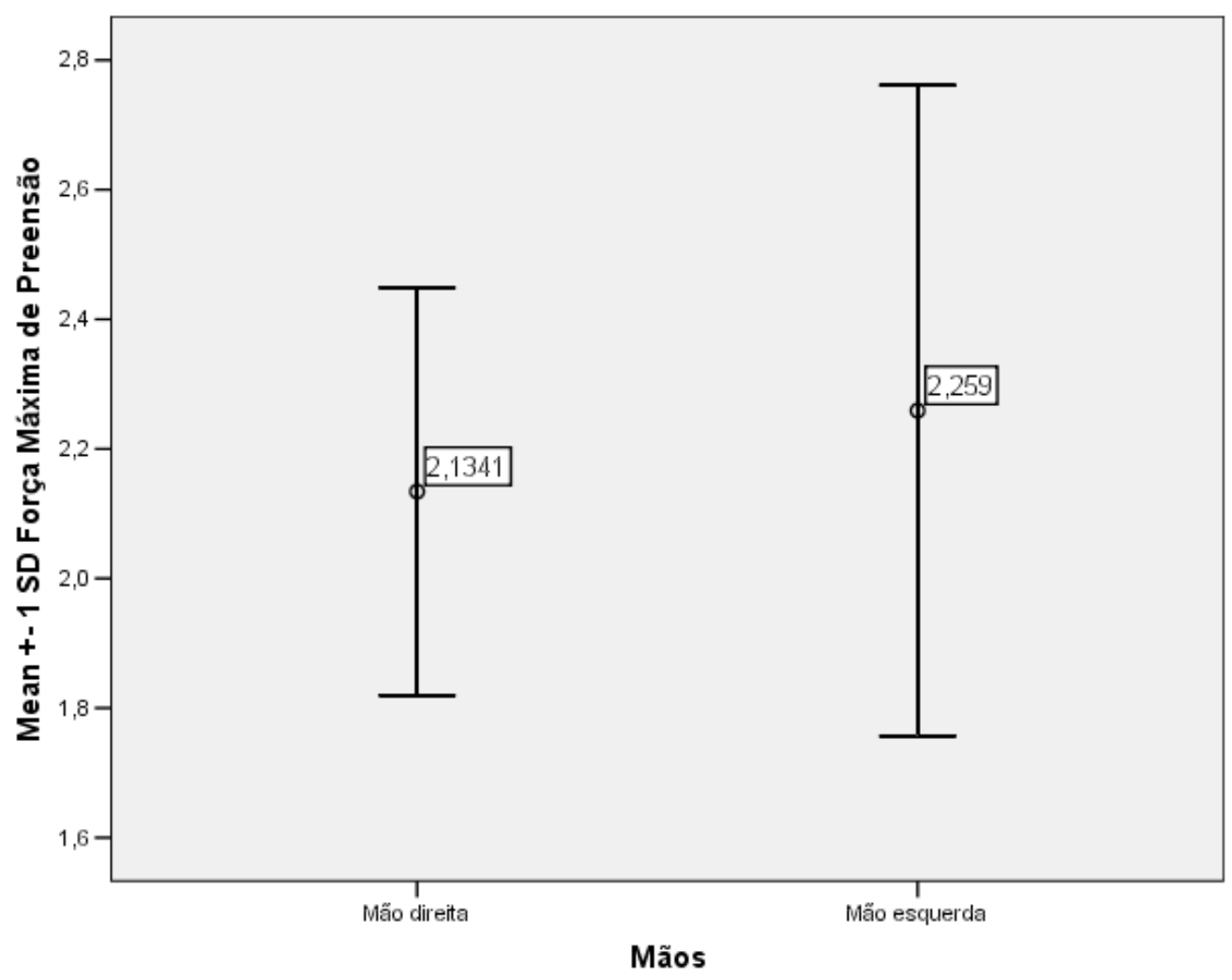


Recém-nascido de termo entre 25-48 horas de vida

Não foi observada diferença significativa da força de preensão entre as mãos ( $t=-1,01, p=0,30)$, assim como entre gênero $(t=0,49, p=0,62)$ e tempo de preensão $(t=-0,318, p=0,75)$. 
Recém-nascido de termo entre 49-72 horas de vida

Não foi observada diferença significativa da variável força de preensão entre as mãos $(t=0,80, p=0,42)$ e tempo de preensão $(t=0,99$, $\mathrm{p}=0,32)$.

$\mathrm{Na}$ variável gênero foi observada diferença significativa $(\mathrm{t}=-5,40$, $p=0,001$ ), sendo que neonatos do gênero feminino apresentaram maior força quando comparados com o gênero masculino (Gráfico 2). 
Gráfico 2. Força de preensão palmar entre gênero masculino e feminino em recém-nascidos de termo entre 49-72 horas de vida

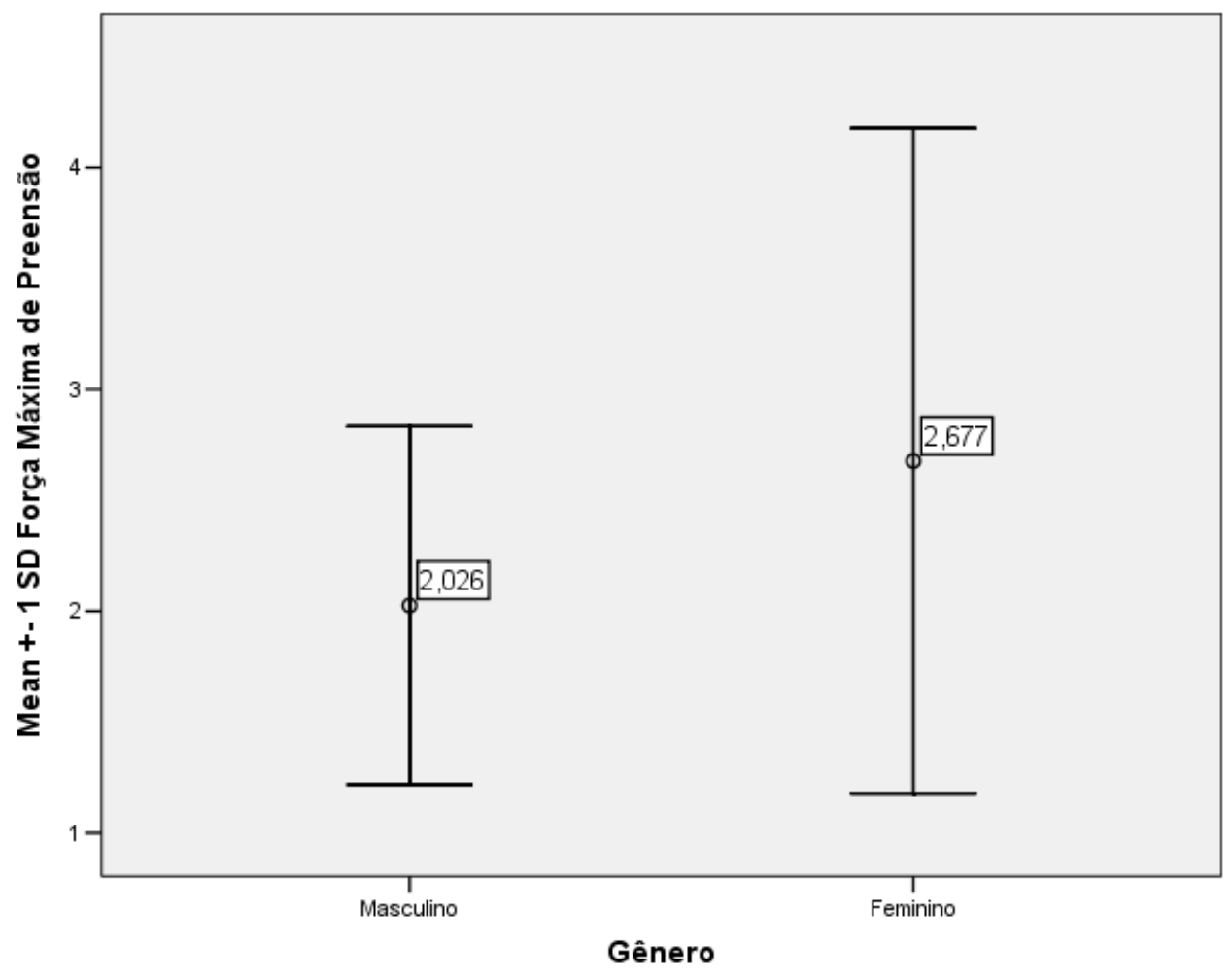


Comparação dos Recém-nascidos de termo entre 12-24h, 25-48h e 4972 horas de vida

Foi observada diferença significativa da força de preensão entre as idades analisadas, sendo que neonatos entre 49-72 horas de vida apresentaram maior força de preensão quando comparados aos neonatos entre 12-24 ( $t=0,22, p=0,01)$ e 25-48 $(t=0,22, p=0,01)$ horas de vida (Gráfico 3).

Na variável tempo de preensão, não houve diferença nas idades entre 12-24h $(t=-0,16, p=1,0), 25-45 h(t=17,5, p=0,62)$ e 49-72h $(t=-0,16, p=$ $1,0)$. 
Gráfico 3. Força de preensão palmar entre recém-nascidos de termo com 12-24h, 25-48h e 49-72 horas de vida

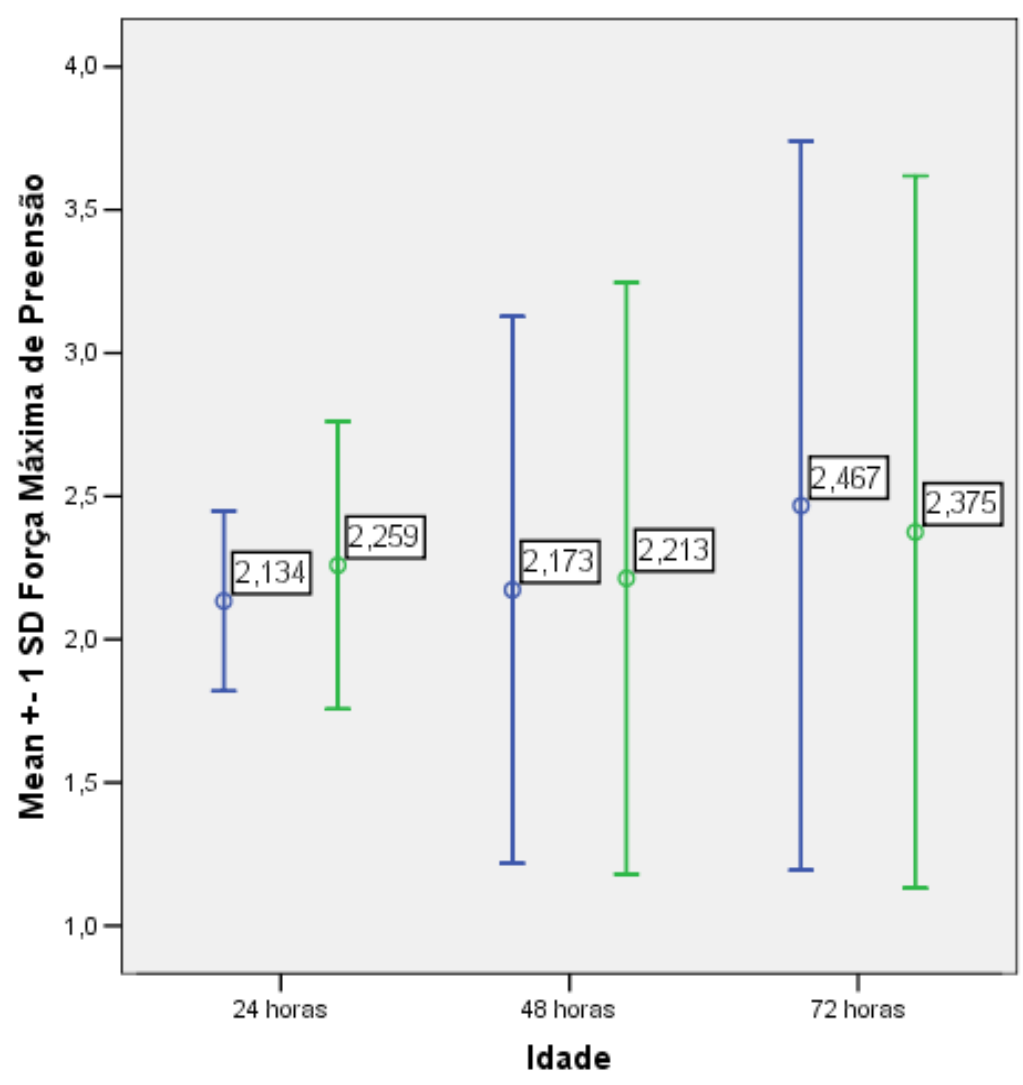




\section{Recém-Nascidos Pré-Termo Tardios}

Foram analisados 87 recém-nascidos pré-termo tardios de ambos os gêneros, com idade gestacional média de $35,91( \pm 0,70)$ semanas, divididos em três subgrupos:

- Grupo 1: 18 recém-nascidos pré-termo tardios com idade média de 20:10 $( \pm 0,26)$ horas de vida;

- Grupo 2: 40 recém-nascidos pré-termo tardios com idade média de 44:33( $\pm 0,22)$ horas de vida;

- Grupo 3: 29 recém-nascidos pré-termo tardios com idade média de 69:32( $\pm 0,31)$ horas de vida. 
Recém-nascidos pré-termo tardios entre 12-24 horas de vida

Não foi observada diferença significativa da força de preensão entre as mãos ( $t=0,32, p=0,74)$, assim como entre gênero $(t=0,21, p=0,82)$ e tempo de preensão $(t=0,84, p=0,4)$. 
Recém-nascidos pré-termo tardios entre 25-48 horas de vida

Não foi observada diferença significativa da força de preensão entre as mãos ( $t=0,97, p=0,32)$, assim como entre gêneros ( $t=1,92, p=0,05)$.

$\mathrm{Na}$ variável tempo de preensão, foi observada diferença significativa $(t=2,30, p=0,02)$, sendo que o gênero masculino apresentou maior tempo de preensão palmar quando comparado ao gênero feminino (Gráfico 4). 
Gráfico 4. Tempo de preensão palmar entre gênero masculino e feminino em recém-nascidos pré-termo tardios entre 25-48 horas de vida

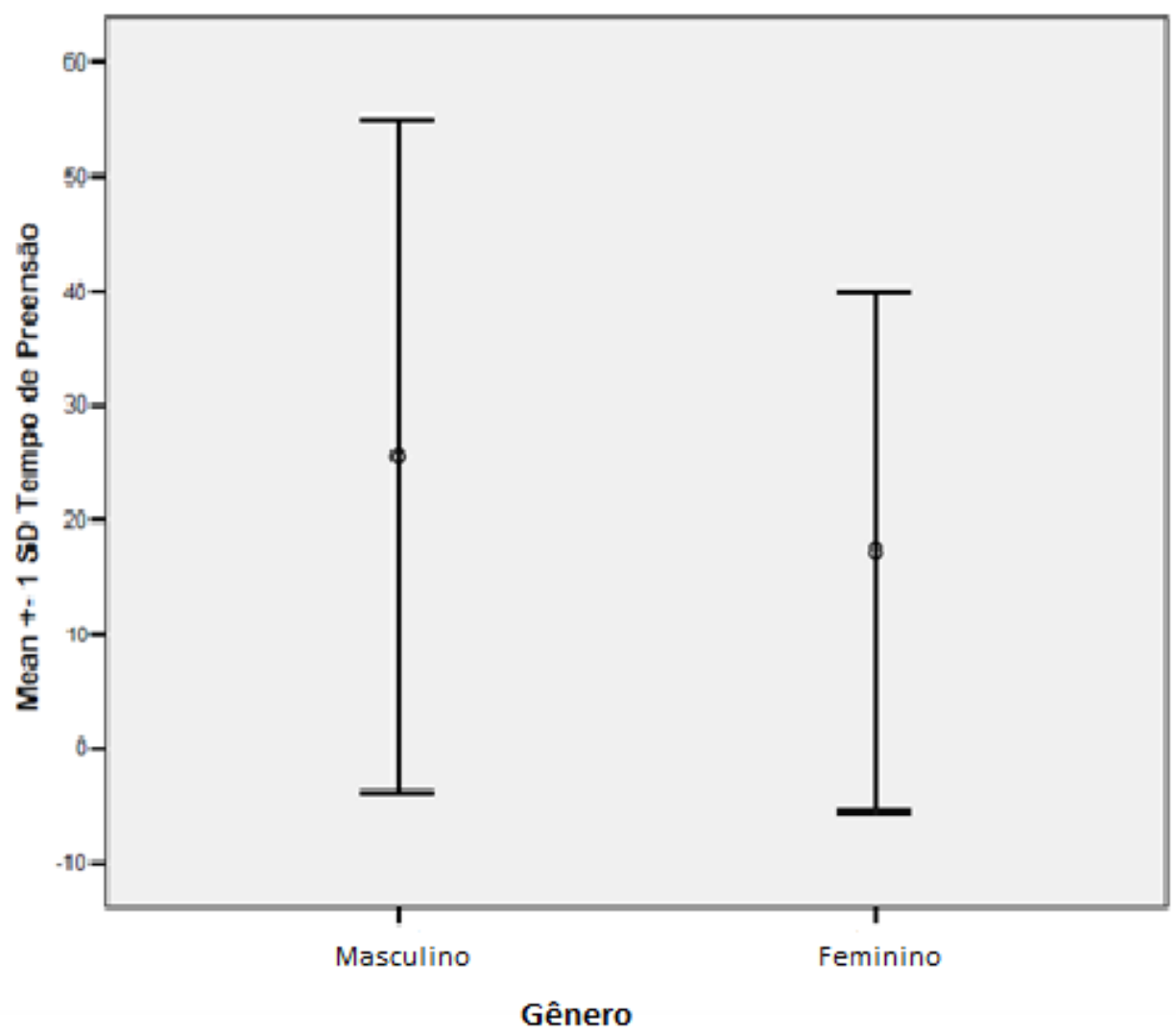


Recém-nascidos pré-termo tardios entre 49-72 horas de vida

Não foi observada diferença significativa da força de preensão entre as mãos $(t=1,25, p=0,21)$ e tempo de preensão $(t=0,40, p=0,68)$.

$\mathrm{Na}$ variável gênero, houve diferença significativa $(t=2,11, p=0,03)$, sendo que o gênero masculino apresentou menor tempo de preensão palmar quando comparado ao gênero feminino (Gráfico 5). 
Gráfico 5. Tempo de preensão palmar entre gênero masculino e feminino em recém-nascidos pré-termo tardios entre 49-72 horas de vida

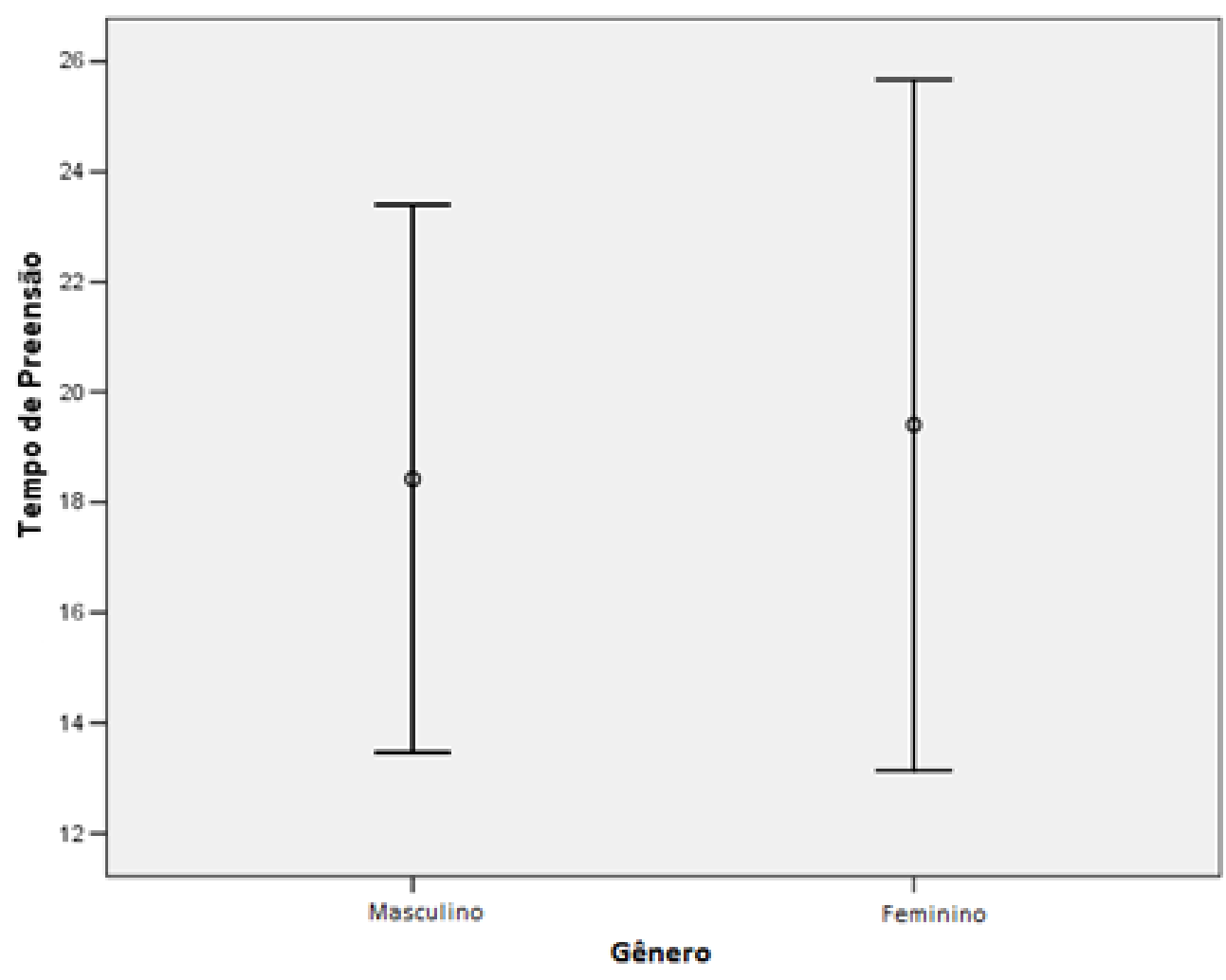


Comparação dos recém-nascidos pré-termo tardios entre 12-24h, 2548h e 49-72 horas de vida

Foi observada diferença significativa da força de preensão entre as idades $(F=3,55, \quad p=0,02)$, sendo que neonatos entre 25-48 horas apresentaram menor força de preensão palmar quando comparados aos neonatos entre 12-24,e 49-72 horas de vida (Gráfico 6). 
Gráfico 6. Força de preensão palmar dos recém-nascidos prétermo tardios entre 12-24h, 25-48h e 49-72 horas de vida

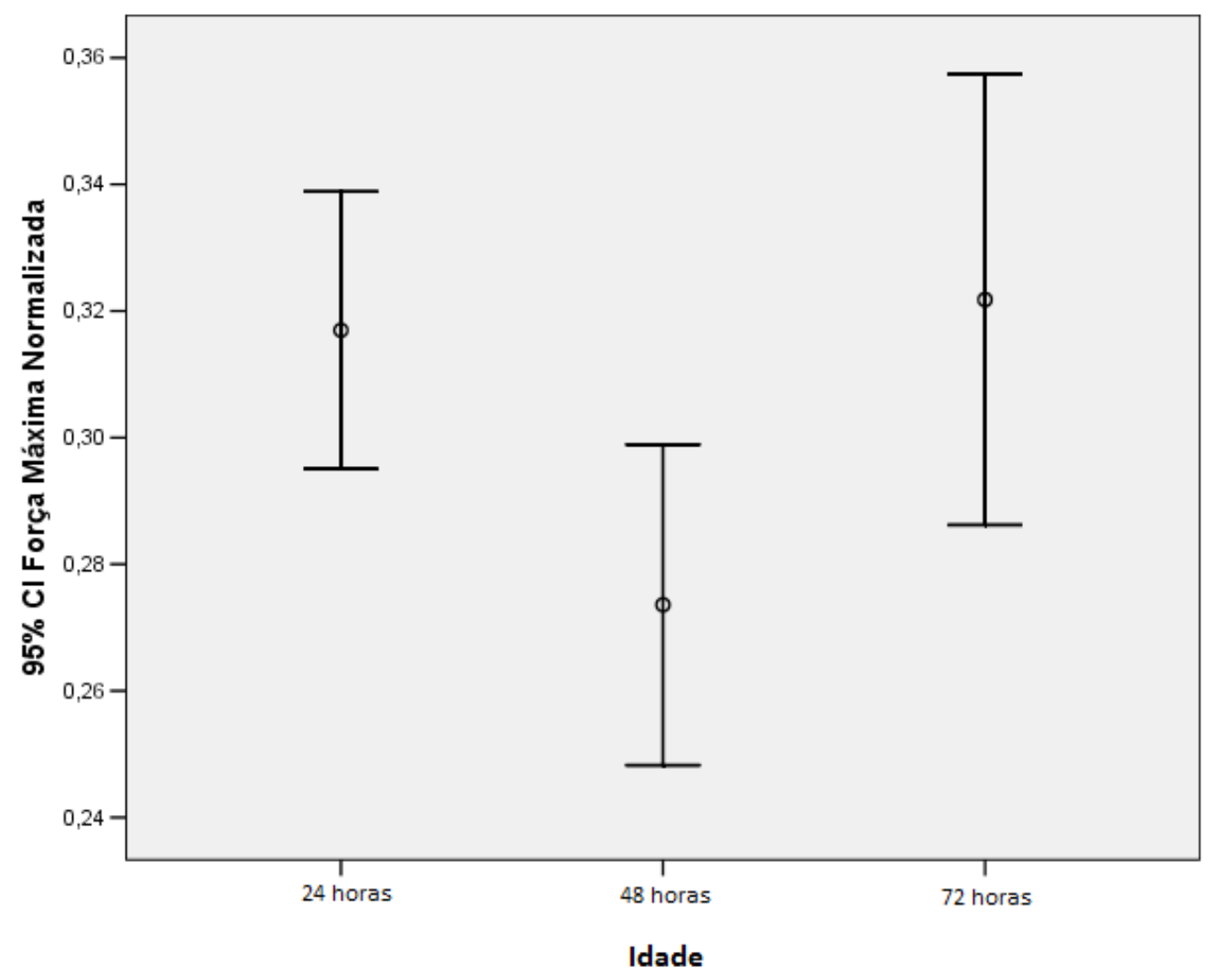


A variável tempo de preensão palmar também apresentou diferença significativa $(F=23,10, \quad p=0,00)$, sendo que neonatos com 12-24h apresentaram maior tempo de preensão palmar em relação aos neonatos entre 25-48h e 49-72 horas de vida (Gráfico 7). 
Gráfico 7. Tempo de preensão palmar dos recém-nascidos prétermo tardios entre $12-24 \mathrm{~h}, 25-48 \mathrm{~h}$ e $49-72$ horas de vida

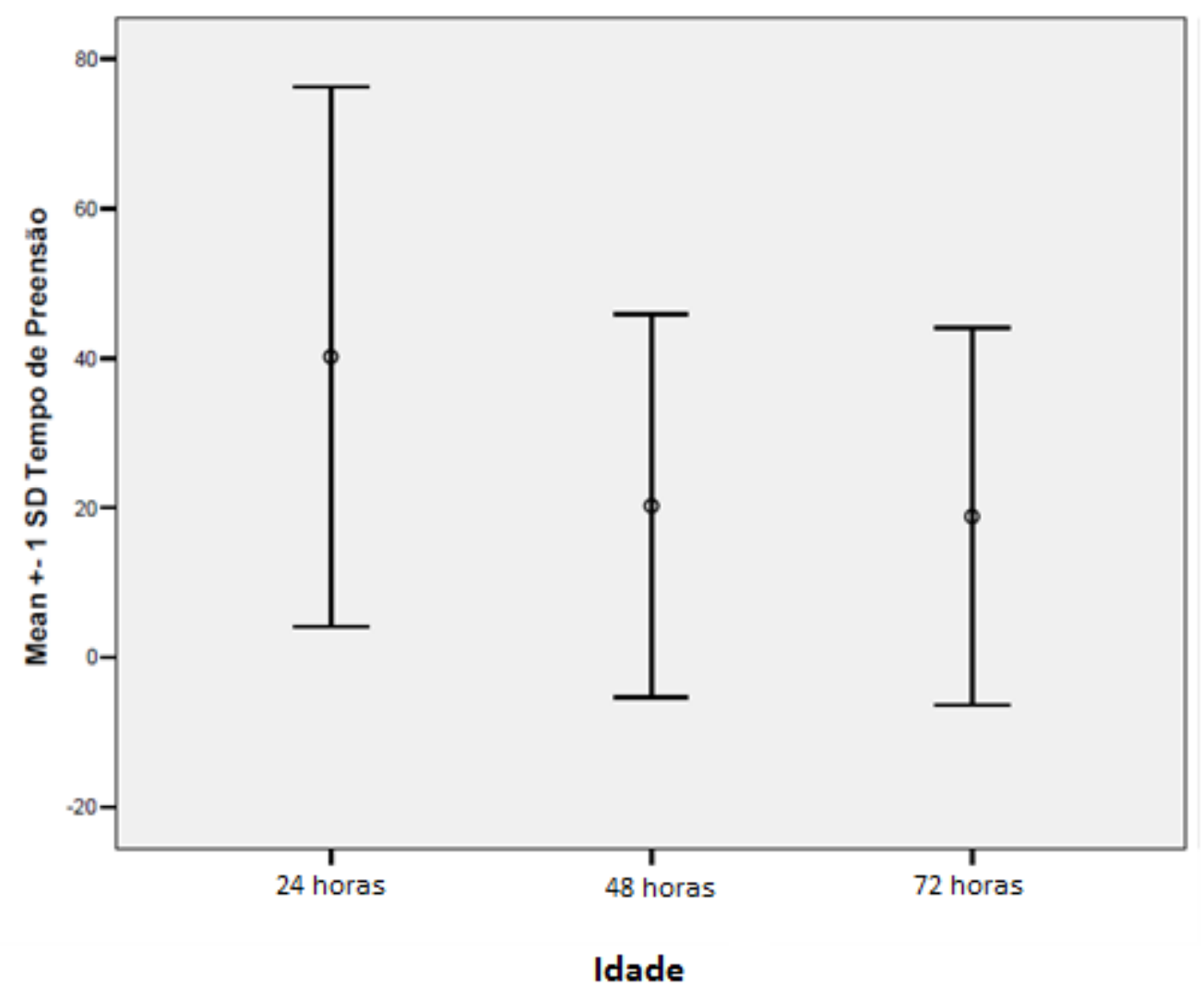


Comparação de recém-nascidos de termo versus pré-termos tardio entre 12-24 horas de vida

Não foi observada diferença significativa da força de preensão palmar entre os grupos $(t=1,90, p=0,05)$ entre 12-24h.

A variável tempo de preensão palmar apresentou diferença significativa entre os grupos $(t=4,64, p=0,00)$, sendo que o grupo pré-termo tardio, apresentou menor tempo quando comparado com o grupo de termo (Gráfico 8). 
Gráfico 8. Comparação do tempo de preensão palmar entre recém-nascido de termo versus pré-termo tardio entre 12-24 horas de vida

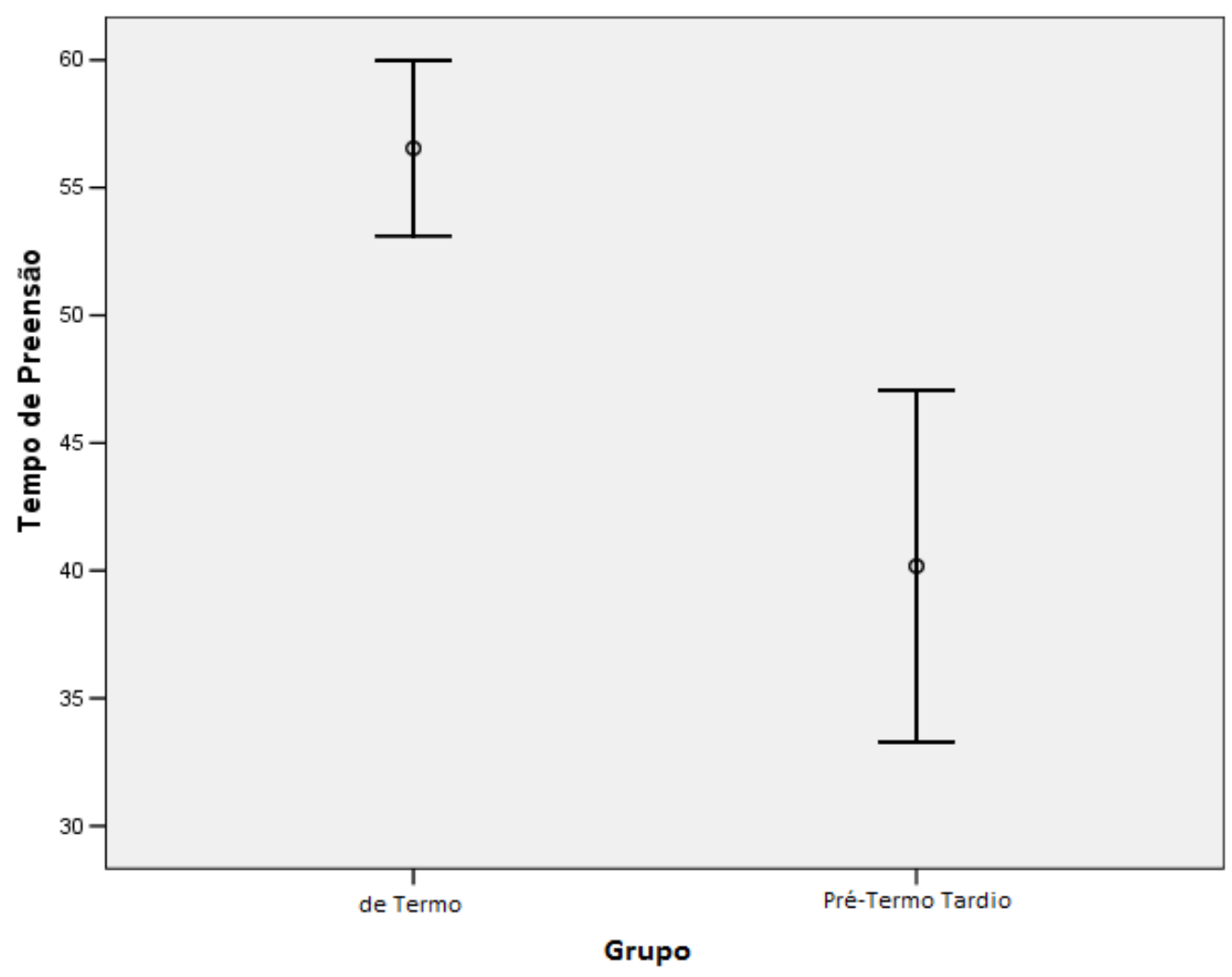


Comparação de recém-nascidos de termo versus pré-termo tardios entre 25-48 horas de vida

Foi observada diferença significativa da força de preensão palmar entre os grupos $(t=2,54, p=0,01)$, sendo que o grupo pré-termo tardio, apresentou menor força, quando comparado com o grupo de termo (Gráfico 9). 
Gráfico 9. Comparação da força de preensão palmar entre recémnascidos de termo versus pré-termo tardios entre 25-48 horas de vida

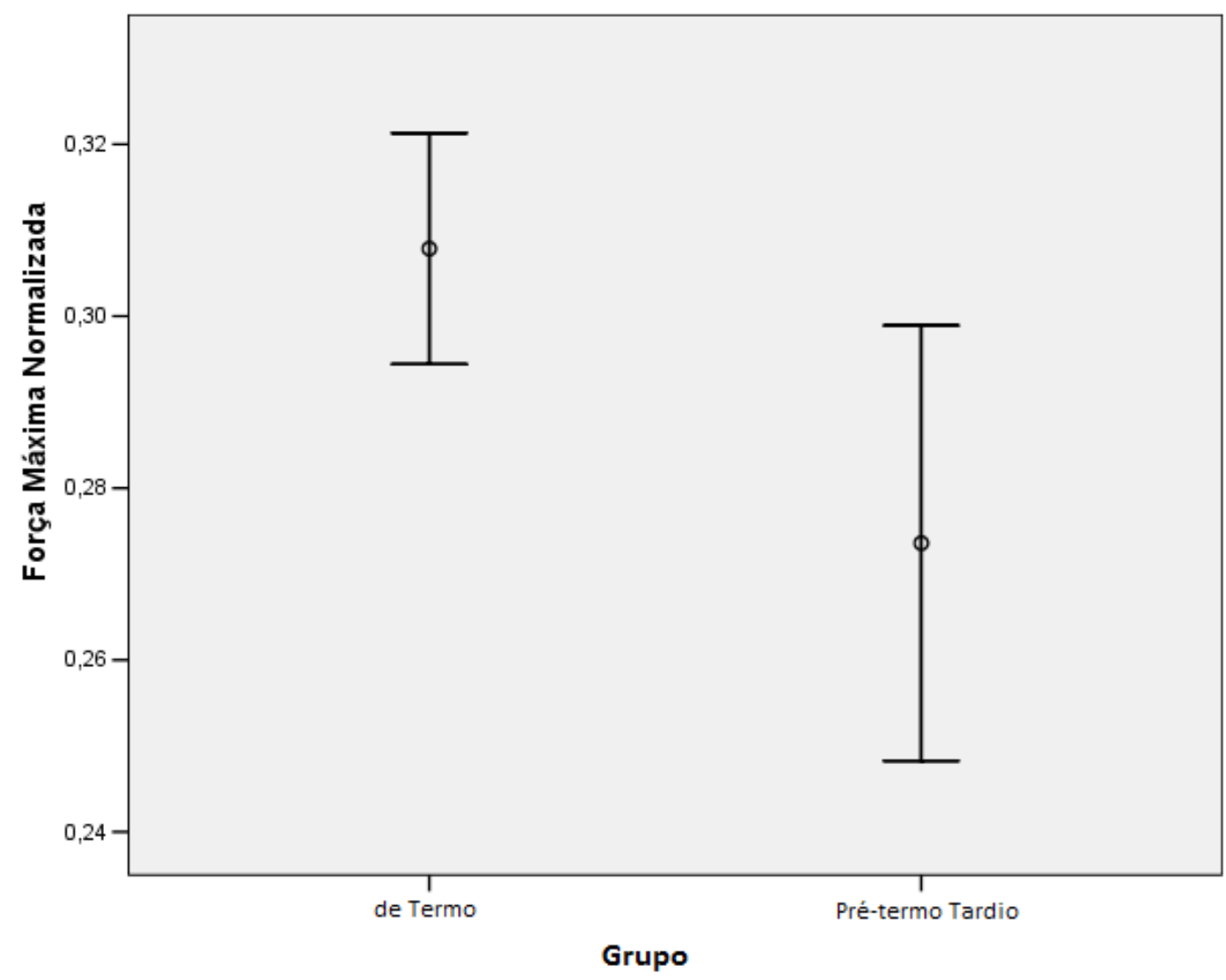


Na variável tempo de preensão palmar, também foi observada diferença significativa entre os grupos $(t=8,02, p=0,00)$, sendo que o grupo pré-termo tardio, apresentou menor tempo, quando comparado com o grupo de termo (Gráfico 10). 
Gráfico 10. Comparação do tempo de preensão palmar entre recém-nascidos de termo versus pré-termo tardios entre 25-48 horas de vida

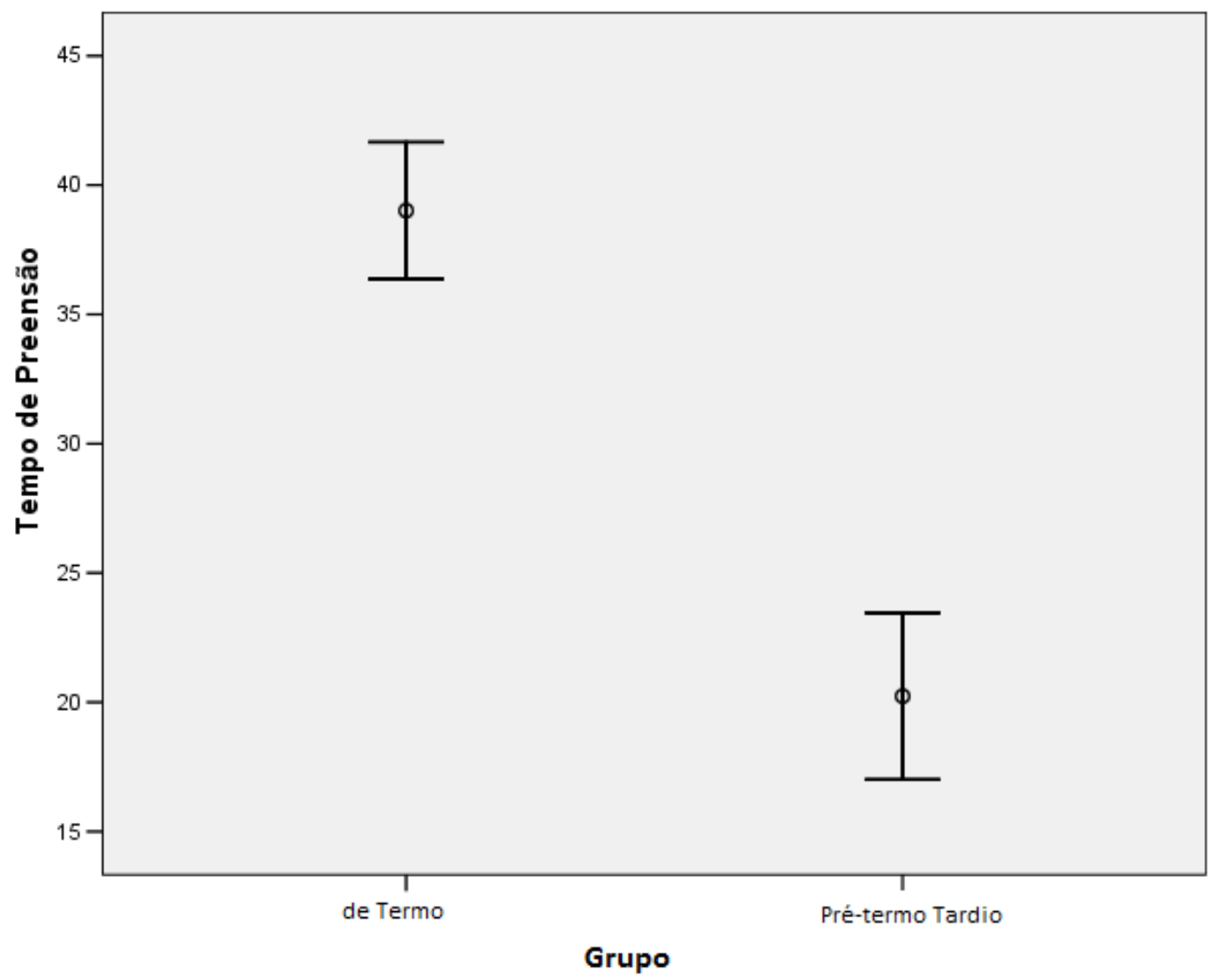


Comparação de recém-nascidos de termo versus pré-termo tardios entre 49-72 horas de vida

Foi observada diferença significativa da força de preensão palmar entre os grupos $(t=0,95, p=0,01)$, sendo que o grupo pré-termo tardio, apresentou menor força, quando comparado com o grupo de termo (Gráfico 11). 
Gráfico 11. Comparação da força de preensão palmar entre recém-nascidos de termo versus pré-termo tardios entre 49-72 horas de vida

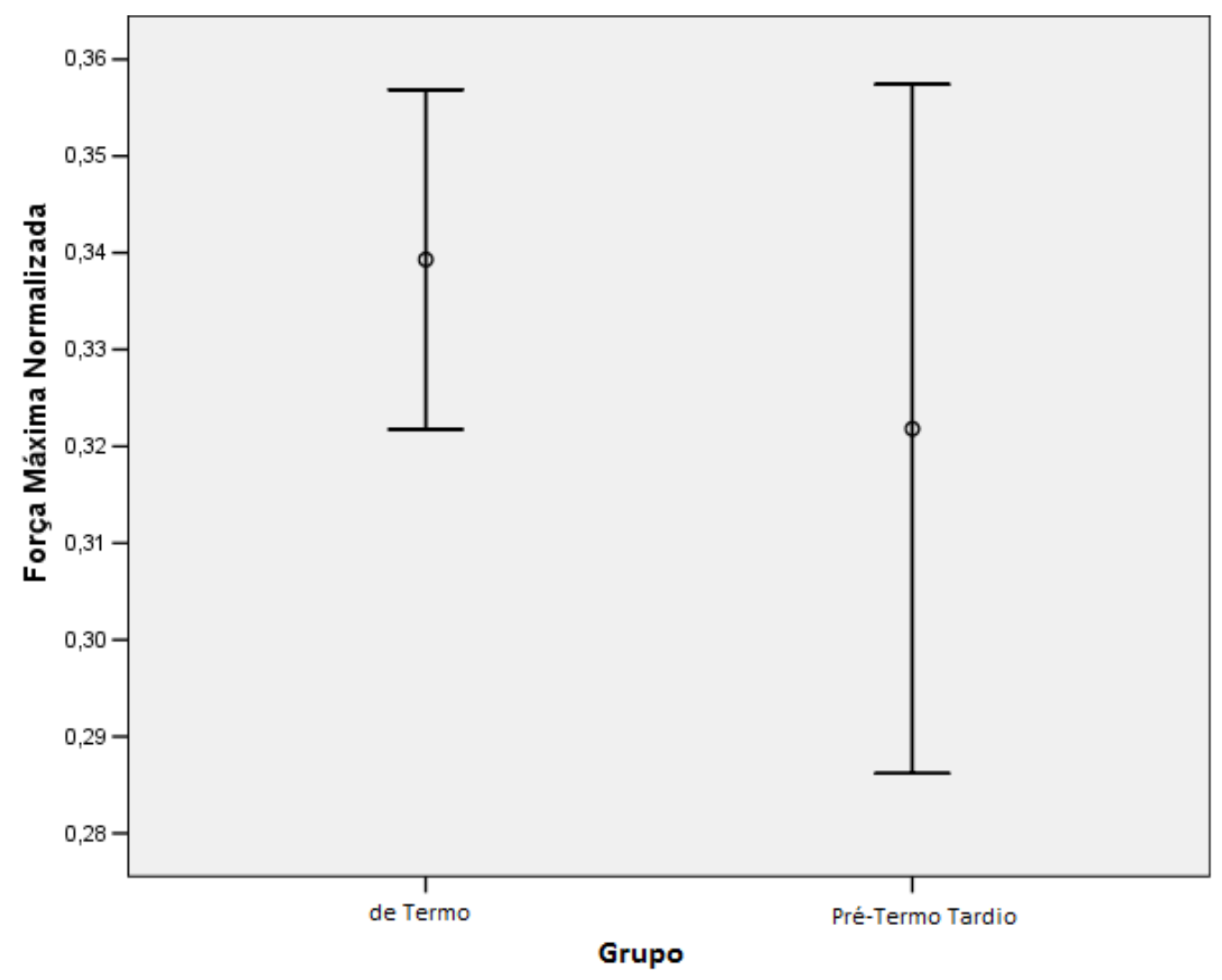


Na variável tempo de preensão palmar, não foi observada diferença significativa entre os grupos $(t=1,84, p=0,06)$ entre $49-72$ horas de vida. 
Comparação entre recém-nascidos de termo e pré-termo tardios com 12-24h, 25-48h e 49-72 horas de vida

Foi observada diferença significativa da força de preensão palmar entre os grupos ( $F=2,67, p=0,00)$ entre 12-24h, 25-48h e 49-72 horas, sendo que o grupo pré-termo tardio apresentou menor força quando comparado ao grupo de termo (Gráfico 12). 
Gráfico 12. Comparação da força de preensão palmar entre recém-nascidos de termo versus pré-termo tardios com 12-24h, 2548h e 49-72 horas de vida

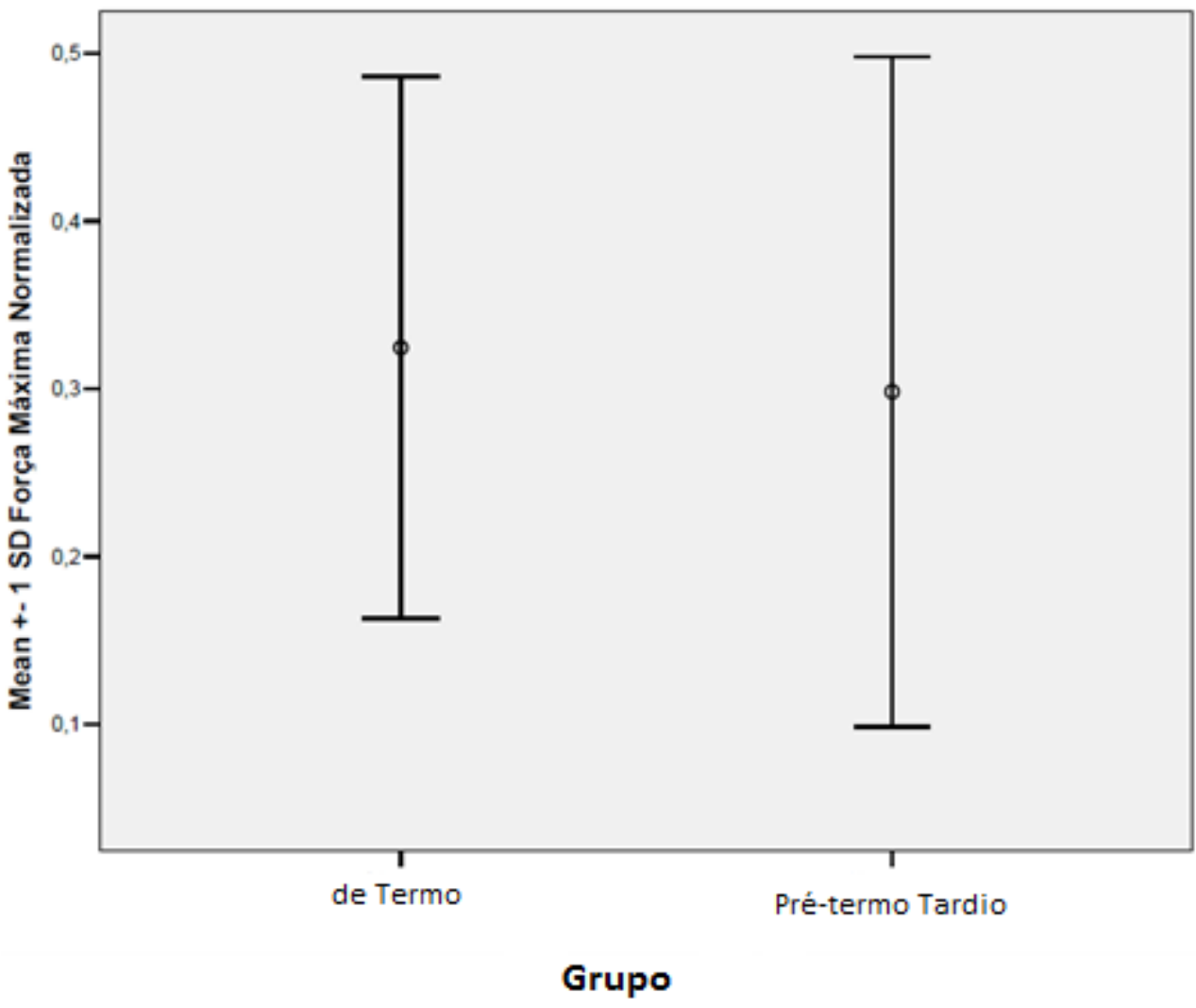


Na variável tempo de preensão palmar, também houve diferença significativa entre os grupos $(F=2,18, p=0,02)$ entre $12-24 h, 25-48 h$ e $49-72$ horas, sendo que o grupo pré-termo tardio, apresentou menor tempo, quando comparado com o grupo de termo (Gráfico 13). 
Gráfico 13. Comparação do tempo de preensão palmar entre recém-nascidos de termo versus pré-termo tardio com 12-24h, 2548h e 49-72 horas de vida

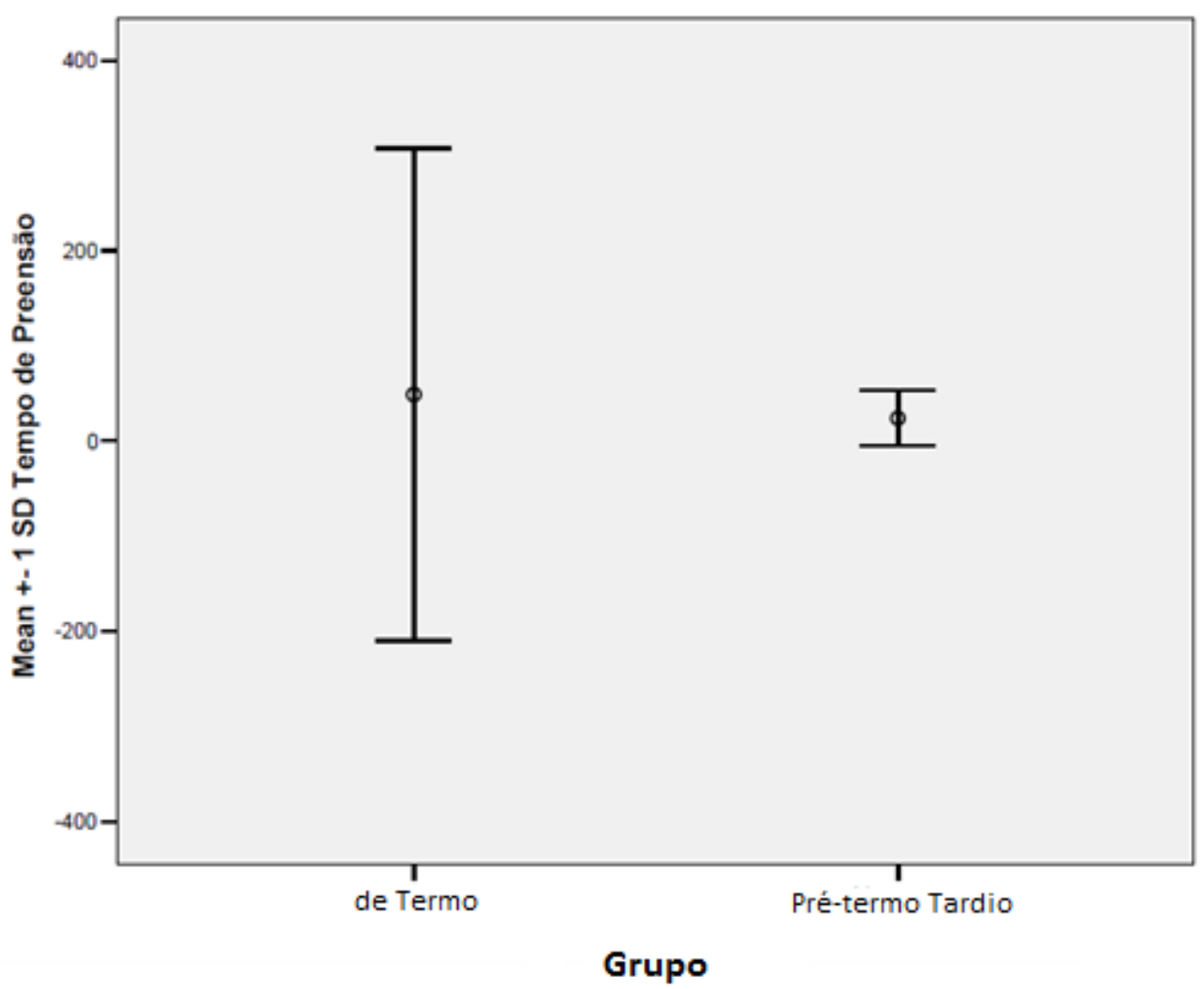




\section{DISCUSSÃO}


Os resultados de nosso estudo demonstraram que a força de preensão palmar de recém-nascidos de termo aumentou gradualmente durante os três períodos analisados.

De acordo com nossa hipótese, neonatos de termo com idade entre 49-72 horas apresentam maior força de preensão palmar quando comparados com neonatos entre 12-24h e 25-48h, devido à adaptação perinatal. Nas últimas 14 semanas de gestação ocorre diminuição do líquido amniótico, fato que ocasiona estresse mecânico, representado pela redução de miosina e desmineralização óssea, sendo o final da gestação um período critico no desenvolvimento muscular e esquelético do feto (Sekulic \& Nainaric, 2005).

Os eventos da adaptação fisiológica pós-natal, tais como estresse mecânico, alterações hemodinâmicas, estabelecimento da diurese, bem como alterações da temperatura ambiental e corpórea e ação da gravidade, são responsáveis por um relativo estado de desorganização e diminuição de peso nos primeiros dias de vida. Esse impacto do meio extra-uterino pode afetar a diferenciação neural e a mielinização das células da glia no recémnascido (Saugstad, 1998).

Da mesma forma, a variabilidade primária, que tem início na vida fetal e é traduzida por reflexos, reações, ajustes posturais, sinergias e movimentos de amplitudes variáveis representando a maturação do SNC, também influencia na alteração da força de preensão palmar (Vles et al., 
1989; Hadders-Algra \& Touwen, 1992). Segundo Hadders-Algra et.al. (2000a) a força de preensão palmar involuntária apresenta-se em forma de "curva" com aumento nos primeiros dias de vida, seguida de declínio gradual até se transformar em movimentos voluntários, indicando maturação cerebral.

Outro fator que provavelmente pode influenciar a força de preensão palmar do recém-nascido é a anestesia materna recebida durante o parto. Este procedimento pode causar diminuição da pressão e do fluxo sanguíneo uterino, com diminuição da perfusão tecidual fetal. Ao comparar o efeito da anestesia com a atividade neurológica em recém-nascidos com dois, quatro e oito horas de vida e um, dois, três, quatro e sete dias de vida, Hollmen et.al. (1978) observaram que nos recém-nascidos de mães anestesiadas houve diminuição da força de sucção e de preensão palmar nos primeiros dois dias de vida, em relação àqueles cujas mães não receberam anestésico. Em nossa casuística observamos aumento significativo da força de preensão palmar no terceiro dia de vida. Como $65 \%$ dos neonatos nasceram de parto cesáreo, é possível que o uso de anestésico nas mães tenha influenciado este comportamento.

Por outro lado, os recém-nascidos pré-termo tardios apresentaram diminuição significativa da força e do tempo de preensão palmar nas primeiras 72 horas de vida. Analisando individualmente cada período observamos diferença significante na força de preensão palmar, sendo esta menor no período de 25-48h seguida de recuperação entre 48-72h a níveis semelhantes das 12-24h. No entanto, a variável tempo de preensão 
apresentou-se menor no segundo e terceiro dia quando comparada com o primeiro dia de vida.

Portanto nos recém-nascidos de termo houve aumento gradual da força de preensão palmar, sem alteração significativa do tempo de preensão. Por outro lado nos pré-termo tardios não houve aumento da força de preensão, observando diminuição do tempo de preensão. Estes resultados reforçam a hipótese de que o recém-nascido de termo e pré-termo tardio apresentam diferenças no comportamento da força de preensão palmar. Estudos adicionais são necessários para esclarecer o comportamento da preensão nos recém-nascidos de diferentes idades gestacionais.

Heidelise et al. (2004) com o objetivo de investigar o efeito da experiência na estrutura e função do cérebro de prematuros com o auxílio do eletroencefalograma, observaram que recém-nascido pré-termo, mesmo quando considerados tardios, são mais vulneráveis a experiências inesperadas e estimulação e desencadeam períodos criticos durante o desenvolvimento do cérebro e dificuldade de adaptação ao meio. Esta situação pode levar à instabilidade neuromotora e possível alteração na função e estruturação do cérebro do prematuro.

Para compensar o menor tempo de permanência no útero os recémnascidos pré-termo utilizam mecanismos compensatórios logo após o nascimento. Dereddy et al. (2008) ao investigarem a maturação acelerada (mielinização) pós-natal em recém-nascidos pré-termo sem alterações neurológicas, observaram baixa condução nervosa motora nos primeiros dias de vida. Após este período houve um aumento gradual, atingindo os 
níveis dos recém-nascidos de termo em torno de dois meses de vida. Esse avanço é atribuído à capacidade do recém-nascido em se adaptar ao ambiente e acelerar o processo de condução.

Em relação à diferença de força de preensão elencada ao gênero, os resultados demonstraram que neonatos de termo do gênero feminino apresentam maior força de preensão palmar quando comparados aos neonatos do gênero masculino no período de 49-72 horas de vida. Uma vez que nos dois primeiros períodos analisados não foi observada diferença significativa, não foi possível demonstrar predomínio de gênero no comportamento da força de preensão palmar. Tan et al. (1992) observaram que recém-nascidos de termo do gênero feminino com dois dias de vida, apresentaram maior força na mão direita quando comparada à mão esquerda, enquanto os neonatos do gênero masculino não mostraram diferença entre as mãos. Os autores atribuíram esse comportamento à lateralidade e modulação hormonal.

DeSmet e Vercamner (2001) ao compararem a força de preensão palmar em crianças de cinco a 15 anos, observaram que essa era semelhante entre os gêneros até 12 anos de idade. Da mesma forma, Hager-Ross e Hosblad (2002) avaliaram a força de preensão palmar de crianças entre quatro e 16 anos e observaram que até os 10 anos os gêneros (feminino e masculino) apresentaram a mesma força de preensão palmar. Outros autores demonstraram que a diferença surge durante a puberdade, aonde a força de preensão palmar chega a ser até $40 \%$ maior no gênero masculino, devido, principalmente, ao aumento dos níveis 
sanguíneos de testosterona (Tan \& Tan, 2001; Yim, Cho \& Lee, 2003, Clerke, Clerke \& Adams, 2005).

Em relação ao comportamento das mãos (direita e esquerda), no grupo de recém-nascidos pré-termo tardios, observamos alta variabilidade da força e tempo de preensão palmar não sendo possível concluir a existência de preferência manual no período de 12-72 horas de vida.

A grande variabilidade encontrada entre gênero (masculino e feminino) e mão (direita e esquerda) no grupo de recém-nascido pré-termo tardio foi similar à observada no grupo de recém-nascidos de termo. A variabilidade é representada pela capacidade do indivíduo responder de várias formas (ação motora) a uma mesma tarefa, determinada por fatores intrínsecos tais como plasticidade cerebral, instabilidade hemodinâmica, alterações musculoesqueléticas e modificações métricas (Saugstad, 1998; Fetters, 2010) e fatores extrínsecos tais como ambiente e características de objetos (Corbetta, Williams \& Snapp-Childs, 2006). Os resultados obtidos por nós corroboram com os autores que afirmam que no período neonatal ocorre variabilidade dos movimentos.

O recém-nascido desenvolve a maturação cerebral através da atividade complexa de circuitos neuronais com mielinização, proliferação, remodelação, arborização dendrítica, sinaptogênese e apoptose (Scher et al. 2003). Juntamente com este processo ocorre a integração ao meio extrínseco gerando aprendizagem e memória e proporcionando estabilidade sináptica (Johnston et al., 2009). 
A grande variabilidade de comportamento de preensão palmar entre as mãos e os gêneros observada em nossa casuística, concorda com os autores que demonstraram que a condições cerebrais do recém-nascido possibilita a utilização de várias estratégias para executar uma tarefa, dentro de um processo adaptativo (Johnston et al., 2009; Fetters, 2010).

Conforme foi mencionado anteriormente, alguns estudos estão sendo realizados com o intuito de comprovar que alterações estruturais, influências hormonais e percepção e adaptação ambiental e espacial interferem na preferência manual (Thelen et al., 1996; Morange \& Bloch, 1996; Out, Van Soest, Savelsbergh \& Hopkins, 1998; Rönnqvist, 2002; Corbetta et al., 2006; Hill \& Khanen, 2009; Hopkins \& Souza, Tudella \& Teixeira, 2011). Apesar de estes trabalhos demonstrarem resultados relevantes, todos os sujeitos eram lactentes e crianças, não sendo possível afirmar que neonatos apresentem este mesmo comportamento.

Assim como os fatores intrínsecos, acredita-se que os fatores extrínsecos tais como iluminação, postura, ruídos, temperatura ambiental, entre outros, possam influenciar na alta variabilidade da ação do recémnascido.

Neste contexto, Toledo e Tudella (2008) ao investigar as características cinemáticas do alcance e apreensão de objetos de lactentes pré-termo dos cinco aos sete meses de vida, observaram alta variabilidade de movimentos lentos e abrangentes no alcance e apreensão, quando comparados com lactentes de termo. Os autores concluíram que esta 
estratégia seria uma adaptação do prematuro perante o meio ambiente e as propriedades do objeto.

Em nosso estudo os fatores ambientais tais como iluminação, ruído, temperatura e posicionamento do recém-nascido, assim como as propriedades do balão de borracha do equipamento, foram controlados e mantiveram-se inalterados. Portanto é provável que a influência destes fatores não tenham desempenhado papel significativo nos resultados observados por nós. Neste sentido, atribuímos a alta variabilidade do comportamento da preensão palmar nos recém-nascidos pré-termo tardios e de termo à adaptação fisiológica pós-natal e plasticidade cerebral.

$\mathrm{Na}$ análise intergrupo observa-se que os recém-nascidos de termo apresentam força e tempo de preensão palmar superior aos recém-nascidos pré-termo tardios em todas as variáveis e idades. Esse resultado confirma nossa hipótese e reflete a dificuldade adaptativa ao meio ambiente do recém-nascido pré-termo, mesmo quando tardio. A imaturidade do desenvolvimento motor traduzida por alterações neuromotoras, hipotonia generalizada e padrão flexor diminuído também está presente neste grupo de neonatos.

Os resultados obtidos por nós no grupo de recém-nascidos pré-termo tardios concorda com o estudo Mouradian et al. (2000) que compararam o comportamento motor (estado de atenção/interação e de auto-regulação e organização comportamental geral) de recém-nascidos pré-termo com aqueles de termo entre 10 a 14 dias de vida. Os autores observaram que recém-nascidos pré-termo, mesmo os considerados tardios apresentam 
diferenças significativas na maioria das variáveis estudadas. Foi destacada a necessidade de avaliação e acompanhamento de cada grupo de recémnascidos conforme sua idade gestacional.

Para confirmar que recém-nascidos pré-termo apresentam alteração neuro-sináptica levando à imaturidade cerebral e que esta é suprida nos primeiros meses de vida, Heathcock et al. (2004) compararam a capacidade de recém-nascidos pré-termo e de termo em desenvolver aprendizagem associativa e habilidades de memória em um período de seis semanas através do movimento de chute. Os autores observaram que os pré-termos apresentam menor frequência de chutes em relação ao grupo de termo, atribuindo este fato à dificuldade em realizar aprendizagem associativa e memória em um curto período.

Mercuri et al. (2003) compararam prematuros saudáveis (divididos em três grupos segundo a idade gestacional) com recém-nascidos de termo aplicando a escala neurológica de Dubowitz, avaliando a movimentação espontânea, tônus muscular e reflexos. Os autores observaram que na maioria dos itens testados, os prematuros apresentaram escores menores quando comparados aos recém-nascidos de termo. Este comportamento foi atribuído possivelmente à hipotonia generalizada, padrão flexor reduzido e alterações sinápticas, concordando com o nosso estudo.

Os neonatos de termo entre 12-24 horas de vida apresentaram força de preensão palmar maior na mão esquerda quando comparada com a mão direita. Alguns autores sugerem que a preferência manual e lateralidade são influenciadas por fatores genéticos e pré-determinadas desde a fase intra- 
uterina (Coryell, 1985; Michel, Sheu \& Brumley, 2002; Hepper, Wells \& Lynch, 2005). Neste contexto, Coren \& Porac (1977) observaram que recémnascidos que realizaram maior ação com o membro superior esquerdo durante a avaliação, apresentaram lateralidade do mesmo membro na fase adulta.

Tan e Tan (1999) observaram que recém-nascidos que apresentaram maior força de preensão palmar da mão esquerda foram predispostos à lateralidade esquerda, enquanto aqueles que apresentaram maior força do lado direito, tornaram-se destros na vida adulta. Em outro estudo, os mesmos autores, ao verificar a influência da testosterona na lateralidade, constataram que recém-nascidos masculinos entre três e cinco dias de vida com maiores níveis de testosterona sanguínea apresentaram maior força de preensão palmar com a mão direita (Tan \& Tan, 2001). Os autores aventaram que níveis elevados de testosterona poderiam dificultar o crescimento do hemisfério cerebral esquerdo, gerando assimetria entre os hemisférios e, consequentemente, induzindo as ações lateralizadas (McCartey \& Hepper, 1999; Tan \& Tan, 2001; Tan \& Tan, 2002; Fink, 2004; Hines, 2006).

Assim como os fatores ontogênicos, a preferência manual também pode ser influenciada por fatores ambientais e posturais. Moraes et al. (2010) ao comparar a força de preensão palmar de lactentes entre zero e 60 dias de vida com a cabeça posicionada em linha média, à esquerda e à direita, observaram que o membro voltado para o lado occipital apresentou maior força de preensão palmar. Outra postura examinada que altera a 
intensidade da preensão palmar e sucção é a postura em prono durante a amamentação, tornando-se um fator positivo de integração entre a mãe, o recém-nascido e o ambiente (Colson et al., 2008).

A preferência manual mostra-se mais madura a partir do segundo semestre do primeiro ano de vida (Caplan \& Kinsbourne, 1976; Ramsay, 1980, Thelen et al., 1996; Out, Van Soest, Savelsbergh \& Hopkins, 1998). Antes deste período, os lactentes alternam as mãos durante o alcance e apreensão dependendo das características e posição do objeto (Morange \& Bloch, 1996; Hill \& Khanen, 2009) e especificidade da tarefa (Corbetta \& Thelen, 1999; Hopkins \& Rönnqvist, 2002; Corbetta et al., 2006). Portanto, o resultado deste estudo sugere que, nas primeiras 72 horas de vida, a preferência manual é indefinida. Consequentemente, a lateralidade não é predisposta e provavelmente se desenvolve após este período, uma vez que não observamos assiduidade por nenhuma das mãos nos primeiros três dias de vida.

O equipamento utilizado no estudo mostrou-se eficaz quanto à captação e apresentação das variáveis força e tempo de preensão auxiliando assim no diagnóstico neuromuscular precocemente. A necessidade de complementar os dados obtidos através do exame neurológico e das escalas motoras na avaliação do comportamento involuntário do neonato foi destacada por Zafeiriou (2004). Da mesma forma, ao descrever os movimentos globais de recém-nascidos e comparar os resultados obtidos com achados de neuro-imagem, Mutlu et al. (2010) sugerem que a avaliação dos movimentos globais contribui para definir o 
prognóstico de desenvolvimento motor, salientando que este método deve ser associado com a avaliação neurológica e exames complementares.

Os resultados obtidos por nós permitiram concluir que há necessidade de avaliar o comportamento da força de preensão palmar através de um equipamento preciso, uma vez que as variações observadas durante este período poderiam passar despercebidas no exame clínico convencional.

Por ser tratar de uma técnica fácil, rápida, não invasiva e pouco dispendiosa, sugerimos que o equipamento seja utilizado como um sinal de alerta para possíveis alterações neuromotoras e também como complemento de exame neurológico no período neonatal.

Uma possível limitação do nosso estudo é o tipo de desenho. A escolha do desenho experimental prospectivo transversal e não longitudinal, permitiu analisar o desenvolvimento da força de preensão palmar apenas nas primeiras 72 horas de vida. Tal tipo de desenho foi escolhido propositalmente. Na literatura atual os estudos sobre o comportamento de preensão palmar são direcionados principalmente a lactentes entre 1-4 meses. Somente as pesquisas de Tan e Tan (1999; 2001) e Moraes et al. (2011) enfocaram o período neonatal, porém analisando neonatos a partir do 15ํ dia de vida. Portanto, constatamos que há uma lacuna na literatura sobre o comportamento de preensão palmar nos primeiros dias de vida, fato que nos levou a realizar o presente estudo nesta faixa etária.

Consideramos que o conhecimento do comportamento de preensão palmar nos recém-nascidos de termo e pré-termo tardios nas primeiras 72 horas de vida é fundamental para a compreensão da evolução posterior. 
Não obstante, a avaliação deste comportamento poderá auxiliar no diagnóstico através da detecção precoce de prováveis mudanças que ocorram ainda no período neonatal, direcionando o neonato para a intervenção. Desta forma o nosso estudo constitui um ponto de partida para pesquisas adicionais na detecção de alterações neurmotoras incluindo crianças desde o nascimento. 
CONCLUSÕES

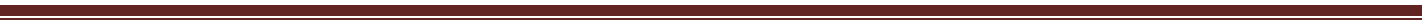


Os resultados obtidos no presente estudo permitiram chegar às seguintes conclusões:

- Houve aumento significativo da força de preensão palmar nas primeiras 72 horas de vida em recém-nascidos de termo.

- Os recém-nascidos pré-termo tardios apresentaram diminuição significativa da força e do tempo de preensão palmar nas primeiras 72 horas de vida.

- Quando comparados com recém-nascidos de termo, os recémnascidos pré-termo tardios apresentaram força e tempo de preensão palmar menor nas primeiras 72 horas de vida.

- Na comparação do comportamento de preensão palmar, não foi possível demonstrar predomínio de gênero, tanto em neonatos de termo quanto em pré-termo tardios.

- Não foi possível afirmar que a preferência manual está prédeterminada desde os primeiros dias de vida em ambos os grupos. 
ANEXOS 


\title{
ANEXO I
}

\section{DESCRIÇÃO DA ANÁLISE PARA SABER O TAMANHO DA AMOSTRA}

\author{
Referências: \\ Bolfarine \\ e \\ Bussab \\ (1994).
}

http://www.lee.dante.br/pesquisa/amostragem/qua_1_media_est.html\#des-pad

Parâmetros necessários são: Desvio-Padrão, Erro máximo da estimativa, Nível de significância.

\section{COM DESVIO PADRÃO de 5}

A parte fracionária do número deve ser separada por ponto ex: 5.21

\section{RESULTADO}

\section{Valores calculados com os dados de entrada}

Desvio padrão: 5.0000

Erro máximo da estimativa: 1.0000

Nível de significância: 5\%

Tamanho da amostra calculado: 96

Para outros valores do nível de significância temos:

$\begin{array}{crr}\text { Nív. de signif. } & \text { Tamanho da amostra } \\ 0.1 \% & 271 & \\ 1 \% & 166 & \\ 10 \% & 67 & \end{array}$




\section{ANEXO II}

HOSPITAL DAS CLÍNICAS DA FACULDADE DE MEDICINA DA UNIVERSIDADE DE SÃO PAULO-HCFMUSP

MODELO DE TERMO DE CONSENTIMENTO LIVRE E ESCLARECIDO

DADOS DE IDENTIFICAÇÃO DO SUJEITO DA PESQUISA OU RESPONSÁVEL LEGAL

1.NOME:

DOCUMENTO DE IDENTIDADE $\mathrm{N}^{\circ}$ SEXO :M $\square \mathrm{F} \square$

DATA NASCIMENTO: ........................

ENDEREÇO

№

APTO:

BAIRRO:

CEP: TELEFONE: DDD CIDADE

2.RESPONSÁVEL LEGAL

NATUREZA (grau de parentesco, tutor, curador etc.)

DOCUMENTO DE IDENTIDADE $\mathrm{N}^{\circ}$ :

SEXO :M $\square \mathrm{F} \square$

DATA NASCIMENTO: ........................

ENDEREÇO

№

APTO:

BAIRRO:

CEP: TELEFONE: DDD CIDADE .)

\section{DADOS SOBRE A PESQUISA}

1. TÍTULO DO PROTOCOLO DE PESQUISA: Análise da força da preensão palmar em recém-nascidos pré-termo e de termo.

2. PESQUISADOR :Dra Vera Lúcia Jornada Krebs CARGO/FUNÇÃO: Médica -Chefe.

INSCRIÇÃO CONSELHO REGIONAL № .CRM 29892

UNIDADE DO HCFMUSP: Berçário Anexo a Maternidade - Instituto da Criança

3. AVALIAÇÃO DO RISCO DA PESQUISA: RISCO MÍNIMO: $\quad \mathbf{X}$ RISCO MÉDIO $\square \quad$ RISCO BAIXO $\square \quad$ RISCO MAIOR $\square$

4. DURAÇÃO DA PESQUISA : 24 meses 


\section{HOSPITAL DAS CLÍNICAS DA FACULDADE DE MEDICINA DA UNIVERSIDADE DE}

\section{SÃO PAULO-HCFMUSP}

1) Estamos realizando um estudo para medir a força da mão do bebê. Todo bebê apresenta força nas mãos ao nascimento, sendo importante avaliar o fechamento das mãos dos bebês para ver se a força está aumentada ou diminuída. Para isso gostaria de sua autorização para incluir seu(sua) filho(a) neste estudo, onde mais

ou menos 200 bebês participarão.

2 ) Para esta avaliação o bebê estará deitado de barriga para cima e segurará um pequeno balão de borracha, primeiro com a mão direita e em seguida com a mão esquerda durante aproximadamente 6 minutos no total e sua cabeça estará posicionada no meio. Enquanto o bebê estiver segurando o pequeno balão, a força da mão será medida com um aparelho simples que mostrará a força em números e figuras.

O teste será realizado somente em um dia entre $24 \mathrm{~h}$ a 72 horas de vida do seu filho, sendo que, se ele nasceu prematuro, ele deverá ter idade gestacional de 34 a 36 6/7. Além da força será medido também o tamanho da mão do bebê com uma fita métrica

3) Não há riscos ou outras complicações e a avaliação não causa nenhum tipo de dor.

4) Autorizando a participação do seu(sua) filho(a) neste estudo, você estará contribuindo para novas descobertas quanto ao desenvolvimento do bebê.

5)A qualquer momento a senhora poderá interromper a participação do seu(sua) filho(a) do estudo. O nome do seu(sua) filho(a) não será revelado e os resultados dos testes serão comunicados a vocês pais ou responsáveis.

Acredito ter sido suficientemente informado a respeito das informações que li ou que foram lidas para mim, descrevendo o estudo "Análise da Força de Preensão Palmar em Recém-Nascidos Pré-Termo e de Termo". Eu discuti com a Dra. Vera Lúcia Jornada Krebs sobre a minha decisão em participar nesse estudo. Ficaram claros para mim quais são os propósitos do estudo, os procedimentos a serem realizados, seus desconfortos e riscos, as garantias de confidencialidade e de esclarecimentos permanentes. Ficou claro também que minha participação é isenta de despesas e que tenho garantia do acesso a tratamento hospitalar quando necessário. Concordo voluntariamente em participar deste estudo e poderei retirar o meu consentimento a qualquer momento, antes ou durante o mesmo, sem penalidades ou prejuízo ou perda de qualquer benefício que eu possa ter adquirido, ou no meu atendimento neste Serviço.

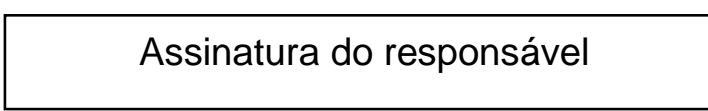

Assinatura do responsável pelo estudo

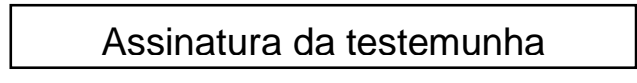

Data $1 / 1$

Em casos de pacientes menores de 18 anos, analfabetos, semi-analfabetos ou portadores de deficiência auditiva ou visual. Declaro que obtive de forma apropriada e voluntária o Consentimento Livre e Esclarecido deste paciente ou representante legal para a participação neste estudo- 


\section{ANEXO III}

Protocolo para coleta de dados

\section{1 ) Antecedentes pessoais}

Nome:

Idade:

Sexo: ( ) M ( ) F

Data de nascimento:.....................

Endereço.

Bairro: Fone:

Nome da mãe: Idade:

Grau de escolaridade: Profissão: Estado Civil:.

\section{2) Antecedentes maternos}

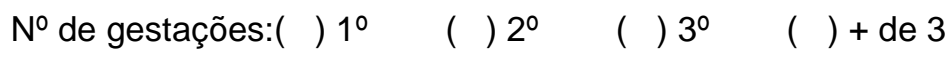

Doenças da mãe: () Não ( ) SimQual:

Anormalidades na gravidez: () Não() SimQual:

Ingestão de tóxicos:( ) Não ( ) Fumo( ) Álcool ( ) Outros.

Ingestão de medicamentos:() Não( )Sim Qual:

Outras intercorrências:

3 ) Dados do Nascimento

Tipo de parto:( ) Normal ( ) Fórceps ( ) Cesariana

Idade gestacional: DUM:........... USG (semanas):

Intercorrências:

4 ) Dados Pós-Natais

Cor:

Capurro:

Apgar:1' 5

Estatura: $\mathrm{cm}$
Gemelar:

Peso Nascimento:

PC: ..cm PIG AIG GIG

Diagnósticos:

Intercorrências:

Alimentação :( ) seio materno ( ) fórmula ( ) mista volume $(\mathrm{ml} / \mathrm{Kg} / \mathrm{d})$ :

Via de alimentação:( ) Oral ( )Sonda gástrica ( ) Mista 


\section{5 ) Avaliação do RNT e RNPT}

\begin{tabular}{|c|c|c|c|c|c|c|}
\hline \multicolumn{3}{|l|}{ Data da Avaliação } & & & & \\
\hline \multicolumn{7}{|c|}{ Última mamada (horas) } \\
\hline \multicolumn{7}{|l|}{ Idade em dias } \\
\hline \multicolumn{7}{|l|}{ IG cronológica } \\
\hline \multicolumn{7}{|l|}{ IG - corrigida } \\
\hline \multicolumn{7}{|l|}{ Estatura ao nascer } \\
\hline \multicolumn{7}{|l|}{ Perímetro Cefálico } \\
\hline \multicolumn{7}{|c|}{ Peso do dia da avaliação } \\
\hline \multicolumn{7}{|c|}{ Estado comportamental } \\
\hline \multicolumn{7}{|c|}{ Tamanho da mão D (cm) } \\
\hline \multicolumn{7}{|c|}{ Circunferência da mão D (cm) } \\
\hline \multicolumn{7}{|c|}{ Tamanho da mão E (cm) } \\
\hline \multicolumn{7}{|c|}{ Circunferência da mão E (cm) } \\
\hline \multicolumn{7}{|c|}{ Início do teste (horas) } \\
\hline \multicolumn{7}{|c|}{ Final do teste (horas) } \\
\hline \multirow[t]{2}{*}{ Preensão Palmar } & & & & & & \\
\hline & MD & ME & MD & ME & MD & ME \\
\hline \multicolumn{7}{|l|}{ Tempo } \\
\hline \multicolumn{7}{|l|}{ Força Máxima } \\
\hline Força Média & & & & & & \\
\hline
\end{tabular}




\section{ANEXO IV}

\begin{tabular}{|l|l|l|}
\hline \multicolumn{2}{|l|}{ Estado Comportamental - Segundo Prechtl e Beintema (1964) } \\
\hline Nível & Nomeação & Descrição \\
\hline $\mathbf{1}$ & Sono Profundo & $\begin{array}{l}\text { Respiração regular, olhos fechados (sem movimentos sob as } \\
\text { pálpebras fechadas), sem atividade espontânea }\end{array}$ \\
\hline $\mathbf{2}$ & $\begin{array}{l}\text { Sono Leve/ } \\
\text { Ativo }\end{array}$ & $\begin{array}{l}\text { Respiração irregular, olhos fechados (movimentos rápidos de olhos } \\
\text { podem ser observados sob as pálpebras fechadas), nível de } \\
\text { atividade baixa, movimentação suave, responde a estímulos internos } \\
\text { e externos }\end{array}$ \\
\hline $\mathbf{3}$ & $\begin{array}{l}\text { Sonolento/ } \\
\text { Intermediário }\end{array}$ & $\begin{array}{l}\text { Respiração regular, olhos abertos ou fechados (pálpebras em } \\
\text { movimentos constantes),nível de atividade variável,pode ou não } \\
\text { haver agitação global motora. }\end{array}$ \\
\hline $\mathbf{4}$ & Alerta Inativo & $\begin{array}{l}\text { Respiração irregular, olhar luminoso, maior tempo de resposta ao } \\
\text { estímulo, atividade motora mínima presente. }\end{array}$ \\
\hline $\mathbf{5}$ & Alerta Ativo & $\begin{array}{l}\text { Atividade motora razoável (movimentos bruscos de extremidades e } \\
\text { sustos espontâneos, reage a estímulos externos aumentando } \\
\text { atividade motora, pode ou não estar choramingando. }\end{array}$ \\
\hline
\end{tabular}


REFERÊNCIAS BIBLIOGRÁFICAS 
Allen MC, Capute AJ. Tone and reflex development before term. Pediatrics. 1990;85:393-9.

Allen MC. Neurodevelopmental outcomes of preterm infants. Curr Opin Neurol. 2008;21:123-8.

Amiel-Tison C. Update of the Amiel-Tison Neurologic Assessment for the Term Neonate or at 40 Weeks Corrected Age. Pediatr Neurol. 2006;27:196-212.

Als H, Duffy FH, McAnulty GB, Rivkin MJ, Vajapeyam S, Mulkern RV, Warfield SK, Huppi PS, Butler SC, Conneman N, Fischer C, Eichenwald EC. Early Experience Alters Brain Function and Structure. Pediatrics. 2004;113:846-57.

Bussab OW, Moretin PA. Estatística básica. São Paulo: Saraiva; 2002.

Caplan PI, Kinsbourne M. Baby drops the rattle: Asymmetry of duration of grasp by infants. Child Dev. 1976;47:532-4. 
Capute AJ, Palmer FB, Shapiro BK, Wachtel RC, Ross A, Accardo PJ. Primitive reflex profile: a quantitation of primitive reflexes in infancy. Dev Med Child Neurol. 1984;26:375-83.

Capute AJ, Accardo PJ. The infant neurodevelopmental assessment: a clinical interpretive manual for CAT-CLAMS in the first two years of life, Part 2. Curr Probl Pediatr. 1996;26:279-306.

Changeux JP. Variation and selection in neuronal function. Trends Neurosci.1997;20:291-3.

Clerke AM, Clerke JP, Adams RD. Effects of hand shape on maximal isometric grip strength and its reliability in teenagers. $J$ Hand Ther. 2005;18:19-29.

Colson SD, Meek JH, Hawdon JM. Optimal positions for the release of primitive neonatal reflexes stimulating breastfeeding. Early Hum Dev. 2008;84:441-9.

Corbetta D, Thelen E. Lateral biases and fluctuations in infant's spontaneous arm movements and reaching. Dev Psychol. 1999;34:237-55. 
Corbetta D, Williams J, Snapp-Childs W. Plasticity in the development of handedness: Evidence from normal development and early asymmetric brain injury. Dev Psychol. 2006;48:460-71.

Coren S, Porac C. Fifty centuries of right-handedness: the historical record. Science.1977;198:631-2.

Coryell, J. Infant rightward asymmetries predict right-handedness in childhood. Neuropsychologia.1985;23:269-71.

DeGroot L. Posture and motility in preterm infants. Dev Med Child Neurol. 2000;42:65-8.

Dereddy NR, Muthusami S, Bhatia BD, Prakash U. H-reflex and motor nerve conduction studies in growth retarded newborn babies. Neurosci Lett. 2008;27;432:188-92.

DeSmet L, Vercammen A. Grip strength in children. J Pediatr Orthop. $2001 ; B(10): 352-4$

Dubowitz L, Mercuri E, Dubowitz V. An optimality score for the neurologic examination of the term newborn. J Pediatr. 1998;133:40616. 
Fallang B, Saugstad OD, Hadders-Algra M. Postural adjustments in preterm infants at 4 and 6 months post-term during voluntary reaching in supine position. Pediatr Res. 2003;54:826-33.

Fetters L. Perspective on variability in the development of human action. Phys Ther. 2010;90:1860-7.

Fink B, Manning JT, Neave N, Tan U. Second to fourth digit ratio and hand skill in Austrian children. Biol Psychol. 2004;67:375-84

Futagi Y, Suzuki Y, Goto M. Clinical significance of plantar grasp response in infants. Pediatr Neurol. 1999;20:111-5.

Geerts WK, Einspieler C, Dibiasi J, Garzarolli B, Bos AF. Development of manipulative hand movements during the second year of life. Early Hum Dev. 2003;75:91-103.

Gesell A, Amatruda CS. The embryology of behavior: the beginnings of the human mind. New York: Harper\& Brothers; 1945.

Glick TH. Toward a more efficient and effective neurologic examination for the 21st century. Eur J Neurol. 2005;12:994-7. 
Guimarães EL, Tudella E. Reflexos primitivos e reações posturais como sinais indicativos de alterações neurossensoriomotoras em bebês de risco. Pediatria(São Paulo). 2003;25:28-35.

Hadders-Algra M, Touwen BC. Minor neurological dysfunction is more closely related to learning difficulties than to behavioral problems. $J$ Learn Disabil.1992;25:649-57.

Hadders-Algra M. The Neuronal Group Selection Theory: a framework to explain variation in normal motor development. Dev Med Child Neurol. 2000a;42:566-72.

Hadders-Algra M. The Neuronal Group Selection Theory: promising principles for understanding and treating development motor disorders. Dev Med Child Neurol. 2000b;42:707-15.

Hadders-Algra M. Two distinct forms of minor neurological dysfunction: perspectives emerging from a review of data of the Groningen Perinatal Project. Dev Med Child Neurol. 2002;44:561-71.

Häger-Ross C, Rösblad B. Norms for grip strength in children aged 416 years. Acta Paediatr. 2002;91:617-25. 
Halpern LF, Brand KL, Malone AF. Parenting stress in mothers of very-low-birth-weight (VLBW) and full-term infants: a function of infant behavioral characteristics and child-rearing attitudes. $J$ Pediatr Psychol. 2001;26:93-104.

Heathcock JC, Bhat AN, Lobo MA, Galloway JC. The performance of infants born preterm and full-term in the mobile paradigm: learning and memory. Phys Ther. 2004;84:808-21.

Hepper PG, Wells DL, Lynch C. Prenatal thumb sucking is related to postnatal handedness. Neuropsychologia. 2005;43:313-5.

Hill EL, Khanem F. The development of hand preference in children: The effect of task demands and links with manual dexterity. Brain Cogn. 2009;7:99-107.

Hines M. Prenatal testosterone and gender-related behavior. Eur $J$ Endocrinol. 2006;155:S115-S121.

Hollmen Al, Jouppila R, Koivisto M, Maatta L, Pihlajaniemi R, Puukka M, Rantakyla P. Neurologic activity of infants following anesthesia for cesarean section. Anesthesiology.1978;48:350-6. 
Hopkins B, Rönnqvist L. Facilitating postural control: Effects on the reaching behavior of 6-month-old infants. Dev Psychol. 2002;40:16882.

Jeng SF, Chen LC, Yau KI. Kinematic analysis of kicking movements in preterm infants with very low birth weight and full-term infants. PhysTher. 2002;82:148-59.

Johnston MV, Ishida A, Ishida WN, Matsushita HB, Nishimura A, Tsuji M. Plasticity and injury in the developing brain. Brain Dev. 2009;31:110.

Lekskulchai R, Cole J. Effect of a developmental program on motor performance in infants born preterm. Aust J Physiother. 2001;47:16976.

McCartney G, Hepper P. Development of lateralized behaviour in the human fetus from 12 to 27 weeks' gestation. Dev Med Child Neurol. 1999;41:83-6.

McGraw MB.The neuromuscular maturation of the human infant. $J$ Nerv Ment Dis. 1944;99:334. 
Mercuri E, Guzzetta A, Laroche S, Ricci D, vanhaastert I, Simpson A, Luciano R, Bleakley C, Frisone MF, Haataja L, Tortorolo G, Guzzetta F, de Vries L, Cowan F, Dubowitz L. Neurologic examination of preterm infants at term age: comparison with term infants. $J$ Pediatr. 2003;142:647-55.

Mercuri E, Ricci D, Pane M, Baranello G. The neurological examination of the newborn baby. Early Hum Dev. 2005;81:947-56.

Miceli PJ, Goeke-Morey MC, Whitman TL, Kolberg KS, Miller-Loncar C, White RD. Brief report: birth status, medical complications, and social environment: individual differences in development of preterm, very low birth weight infants. J Pediatr Psychol. 2000;25:353-8.

Michel GF, Sheu C, Brumley MR. Evidence of a right-shift factor affecting infant hand-use preferences from 7 to 11 months of age as revealed by latent class analysis. Dev Psychol. 2002;40:1-13

Moraes MVM, Tudella E, Ribeiro J, Beltrame TS, Krebs RJ. Reliability of the M-FLEX: Equipment to measure palmar grasp strength in infants. Infant Behav Dev. 2011;34:226-34. 
Morange $\mathrm{F}$, Bloch $\mathrm{H}$. Lateralization of the approach movement and the preension movement in infants from 4 to 7 months. Early Dev Parenting.1996;5:81-92.

Mouradian LE, Als H, Coster WJ. Neurobehavioral functioning of healthy preterm infants of varying gestational ages. J Dev Behav Pediatr._2000;21:408-16.

Mutlu A, Livanelioglu A, Korkmaz A. Assessment of "general movements" in high-risk infants by Prechtl analysis during early intervention period in the first year of life. Turk J Pediatr. 2010;52:6307.

Olhweiler L, Silva AR, Rotta NT. Estudo dos reflexos primitivos em pacientes recém-nascidos pré-termo normais no primeiro ano de vida. Arq Neuropsiquiatr. 2005;63:294-7.

Out L, Van Soest AJ, Savelsbergh GJP, Hopkins B. The effect of posture on early reaching movement. Infant Behav Dev. 1998;30:26072.

Pedroso FS, Rotta NT. From the foot-mouth reflex to the hand- mouth reflex: a continuum of responses to appendicular compression. Arq Neuropsiquiatr. 1997;55:186-92. 
Prechtl HFR, Beintema DJ. The neurological examination of the full term newborn infant. Clin Dev Med.1964;12:1-73.

Prechtl HFR. Qualitative changes of spontaneous movements in fetus an preterm infant are a marker of neurological dysfunction. Early Hum Dev. 1990;23:151-8.

Ramsay DS. Onset of unimanual handedness in infants. Infant Behav Dev. 1980;3:377-85.

Rieko T, Konishi Y, Arend FB, Christa E. Preterm to early post-term changes in the development of hand-mouth contact and other motor patterns. Early Hum Dev. 2003;72:193-202.

Romeo DM, Cioni M, Guzzetta A, Scoto M, Conversano M, Palermo F, Romeo MG, Mercuri E. Application of a scorable neurological examination to near-term infants: longitudinal data. Neuropediatrics. 2007;38:233-8.

Souza RM, Tudella E, Teixeira L. Manual preference in infants reaching as a function of spatial target location. Psicol Reflex Crit. 2011;24:318-25. 
Saugstad LF. Cerebral lateralisation and rate of maturation. Int $J$ Psychophysiol. 1998;28:37-62.

Sekulic SR, Lukac DD, Naumovic NM. The fetus cannot exercise like an astronaut: gravity loading is necessary for the physiological development during second half of pregnancy. Med Hypotheses. 2005;64:221-8.

Scher MS, Jones BL, Steppe DA, Cork DL, Seltman HJ, Banks DL.Functional brain maturation in neonates as measured by EEGsleep analyses. Clin Neurophysiol. 2003;114:875-82.

Shirley MM. The first two years: a study of twenty-five babies: Postural and locomotor development. Greenwood Press.1973;101:703-48.

Tan U, Örs R, Kürkçüoglu M, Kutlu N, Çankaya A. Lateralization of the grasp reflex in male and female human newborns. Int $J$ Neurosci. 1992;62:155-63.

Tan U, Tan M. Incidences of asymmetries for the palmar grasp reflex in neonates and hand preference in adults. Neuroreport.1999;10:3253-6. 
Tan U, Tan M. Testosterone and grasp-reflex differences in human neonates. Laterality. 2001;6:181-92.

Tan U. Grasp-reflex in human neonates: distribution, sex difference, familial sinistrality, and testosterone. A Neuropsychological Perspective. 2002;l:63-82.

Thelen E, Corbetta D, Spencer JP. Development of reaching during the first year: role of movement speed. J Exp Psychol Hum Percept Perform. 1996;22:1059-76.

Toledo AM, Tudella E. The development of reaching behavior in lowrisk preterm infants. Infant Behav Dev. 2008;31:398-407

Tudella E, Oish J, Bergamasco NHP. The effect of oralgustatory,tactile-bucal and tactile-manual stimulation on the behavior of the hands in newborns. Dev Psychobiol. 2000;37:82-9.

Vles JHS, Kingma H, Caberg H, Daniels H, Casaer P. Posture of lowrisk preterm infants between 32 and 36 weeks postmenstrual age. Dev Med Child Neurol. 1989;31:191-5.

Walterfang M, Velakoulis D. Cortical release signs in psychiatry. Aust New Zealand. J Psychiatr. 2005;39:317-27. 
Weiss SJ. Haptic perception and the psychosocial functioning of preterm, low birth weight infants. Infant Behav Dev. 2005;28:329-59.

Yim SY, Cho JR, Lee IY. Normative data and developmental characteristics of hand function for elementary school children in Suwon area of Korea: grip, pinch and dexterity study. J Korean Med Sci. 2003;18:552-8.

Zafeiriou DI, Tikoulas IG, Kremenopoulos GM. Prospective Follow-up of Primitive Reflex Profilesin High-Risk Infants: Clues to an Early Diagnosis of Cerebral Palsy. Pediatr Neurol. 1995;13:148-52.

Zafeiriou DI. Primitive reflexes and postural reactions in the neurodevelopmental examination. Pediatr Neurol. 2004;3:1-8.

Zurich KS. Early motor development in preterm children. The Development of Coordination in Infancy.1993;16:426-44. 